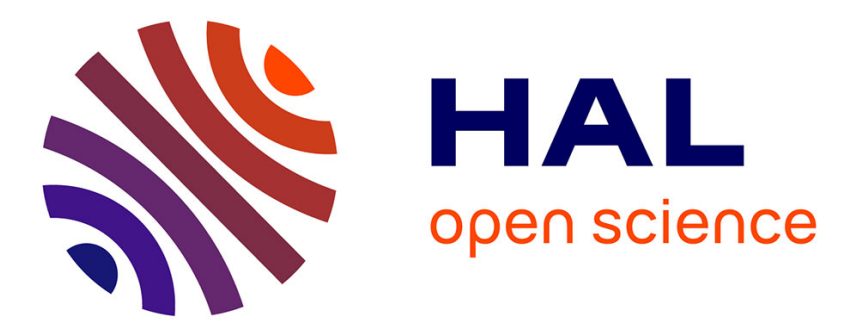

\title{
Modelling of process parameters in laser polishing of steel components using ensembles of regression trees
} Andrés Bustillo, Eneko Ukar, Juan José Rodriguez, Aitzol Lamikiz

\section{To cite this version:}

Andrés Bustillo, Eneko Ukar, Juan José Rodriguez, Aitzol Lamikiz. Modelling of process parameters in laser polishing of steel components using ensembles of regression trees. International Journal of Computer Integrated Manufacturing, 2011, 24 (08), pp.735-747. 10.1080/0951192X.2011.574155 . hal-00719870

\section{HAL Id: hal-00719870 \\ https://hal.science/hal-00719870}

Submitted on 22 Jul 2012

HAL is a multi-disciplinary open access archive for the deposit and dissemination of scientific research documents, whether they are published or not. The documents may come from teaching and research institutions in France or abroad, or from public or private research centers.
L'archive ouverte pluridisciplinaire HAL, est destinée au dépôt et à la diffusion de documents scientifiques de niveau recherche, publiés ou non, émanant des établissements d'enseignement et de recherche français ou étrangers, des laboratoires publics ou privés. 


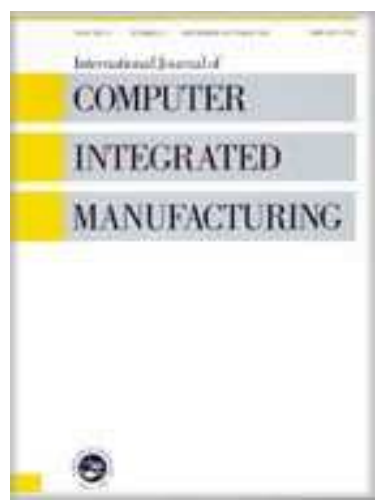

\section{Modelling of process parameters in laser polishing of steel components using ensembles of regression trees}

\begin{tabular}{|r|l|}
\hline Journal: & International Journal of Computer Integrated Manufacturing \\
\hline Manuscript ID: & TCIM-2010-IJCIM-0180.R1 \\
\hline Manuscript Type: & Original Manuscript \\
\hline Author: & 10 -Mar-2011 \\
\hline & $\begin{array}{l}\text { Complete List of Authors: } \\
\text { Bechanical Engineering } \\
\text { Rodriguez, Juan; University of Burgos, Department of Civil } \\
\text { Engineering } \\
\text { Lamikiz, Aitzol; University of the Basque Country, Department of } \\
\text { Mechanical Engineering }\end{array}$ \\
\hline Keywords: & LASERS, REGRESSION ANALYSIS, SURFACE ROUGHNESS \\
\hline Keywords (user): & Ensembles, Process optimization \\
\hline &
\end{tabular}

\section{SCHOLARONE \\ Manuscripts}




\title{
Modelling of process parameters in laser polishing of steel components using ensembles of regression trees
}

\begin{abstract}
Laser polishing of steel components is an emergent process in the automation of finishing operations in the industry. The aim of this work is to develop a soft computing tool for surface roughness prediction of laser polished components. The laser polishing process depends primarily on three factors: surface material, initial topography and energy density. Although the first two factors can be reasonably estimated, the third one is often unknown under real industrial conditions. The modeling tool developed solves this limitation. The application is composed of 4-stages: a data-acquisition system, a dataset generated from the inputs, a soft computing model trained and validated with the dataset. Finally, the model obtained is used to generate different plots of industrial interest. Different prediction models are tested until the most accurate one is selected, in order to generate the soft computing model, and due to the highly complex phenomena that influence surface roughness generation in laser polishing. Ensembles of regression trees yield the best results for the methods under consideration (Multilayer Perceptrons, RBF Networks and Support Vector Machines). It has been proven that the results of an ensemble, which is a combination of several models, are better than single methods in many applications.
\end{abstract}

Keywords: surface finishing, laser polishing, ensembles, process optimization.

\section{Introduction.}

Manufacturing of short series and even single, high complexity components is currently one of the most difficult challenges in manufacturing engineering. Moreover, it is very difficult to obtain customer quality and lead time requirements whilst maintaining a competitive cost. In recent years, Rapid Manufacturing processes (RM) have emerged as an alternative to conventional processes, in order to obtain high complex and fully functional parts [Tuck, 2007]. RM processes have improved the mechanical properties of manufactured parts [Brinksmeier, 2010] and in most cases meet the quality standards demanded by customers. These types of processes are successfully used in different sectors such as, implant manufacturing, highly complex parts in the aerospace industry and some engine and exhaust components in motor racing vehicles. 
One of the most widespread applications of RM processes is found in the manufacturing of small-medium injection moulds or small inserts for larger moulds, as these processes allow complex internal cooling conduits to be built that follow the surface of the part, which can reduce the cooling time of the injected plastic parts by over $30 \%$ [Sriram, 2007].

In the last few years, different RM techniques have been developed, mainly for metal deposition applications. These techniques include: Laser Engineered Net Shaping (LENS) [Weiping, 2003], Selective Laser Sintering (SLS) [ÓDonnchadha, 2004] [King, 2003] or Selective Laser Melting [Kruth, 2004], which build up fully functional metal parts from raw powder material. The main advantages are the reduction in manufacturing-time and the possibility of building parts comprised of very complex geometries.

RM processes allow the fabrication of complex parts in different materials (polymers, ceramic and some metallic alloys). However, one of the major disadvantages for all RM processes is poor surface quality [Lü, 2001]. Mean surface roughness values for RM depend on the process and the particle size of the powder [Santos, 2006] [Levy, 2003], thus, for SLS surfaces, values of between $5 \mu \mathrm{m}$ and $7 \mu \mathrm{m} \mathrm{R}_{\mathrm{a}}$ are usual [Lamikiz, 2007]. However, average specifications for injection moulds are now less than $1 \mu \mathrm{m} R_{a}$ [Lï, 2001]. Some works have attempted to improve the surface quality of the parts using a combination of different manufacturing strategies or post processing [Ahn, 2007] [Ahn, 2009], but there are at present very few effective solutions to improve surface finishing. The same manual abrasive techniques used in machined moulds are employed, in order to achieve the final finishing requirements in parts made by SLS, which would otherwise be time consuming and expensive tasks. 
One alternative to improve the surface finishing of Rapid Manufactured parts is the laser polishing process, since many RM processes use a laser to build parts. The results of studies on the laser polishing of Rapid Manufactured parts are presented in [Lamikiz, 2007] [Ramos-Grez, 2004] [Kruth, 2008]. Experimental results in [Lamikiz, 2007] demonstrate that laser polishing can obtain $1 \mu \mathrm{m} \mathrm{R}_{\mathrm{a}}$ surfaces on SLS parts that present an initial roughness of $8 \mu \mathrm{m} \mathrm{R}_{\mathrm{a}}$. However, the experimental results show some dispersion of the roughness reduction ratio depending on the process parameters and initial surface topography. Also under real industrial conditions, other process parameters should be considered, -including assistance gas, overlapping index, beam incidence angle, etc. The introduction of these parameters requires a more thorough examination of the complexities involved, in order to understand the final roughness of the polished component. Interest in laser polishing goes beyond RM applications. In conventional mould and die manufacturing, based on machining operations, one of the most costly and time consuming tasks is the polishing operation. Polishing can take even more than $30 \%$ of the total manufacturing time [Huissoon, 2002]. Adopting a more generalist approach, two different materials were considered: SLS parts and Orvar Supreme steel parts. Therefore, the data on a series of laser polishing operations applied to SLS and Orvar Supreme steel parts with a $\mathrm{CO}_{2}$ laser are processed with the aim of developing a soft computing tool that can provide information on the influence of each parameter as well as quantify this influence to predict final roughness under new process conditions.

There are different approaches involved in building a model that allows parameter optimization of laser polishing. On the basis of their origin, models have been divided by Kumar [Kumar, 2008] into three categories: empirical models, analytical models, and artificial intelligence, or soft computing models. Soft computing represents 
a collection of computational techniques, which analyse very complex phenomena. The most common soft computing techniques applied to laser manufacturing problems include Artificial Neural Networks [Yousef, 2003] and Particle Swarm [Ciurana, 2008] for laser milling, or adaptive neuro-fuzzy inference models for laser surface treatments [Perez, 2010] and laser cutting [Subramonian, 2009]. To improve the results of independent soft computing methods, a combination of two or more models can be built to improve overall model accuracy. These combinations are called Ensembles. In an ensemble, its prediction ability is built by combining the predictions of the combined models. Ensembles have demonstrated their superiority over single models in many applications. For instance, [Yü, 2009] uses ensembles to identify out-of-control signals in multivariate processes, in [Liao, 2008] they are used for grinding wheel condition monitoring while [Cho, 2010] and [Bisaeid, 2009] uses ensembles for end milling condition monitoring and simultaneous detection of transient and gradual abnormalities in end milling.

The scheme of the soft computing tool is presented in Figure 1. It is composed of 4 modules. The first module collects all the physical information from a series of laser polishing operations. A set of experimental tests was performed, in order to study the potential of the laser polishing process, combining different power levels, feed rates, and focal offset distances in a set of single polishing tracks with a 2,500W $\mathrm{CO}_{2}$ laser on two different materials typically used in mould manufacturing. The second module generates a dataset from the process parameters measured by the first module. There are multiple variables that have an influence on the polishing process and should be considered as inputs for the modelling tool. Some variables are directly collected from the experiment such as the polished material, focal offset distance, laser power, feed rate or initial roughness. Other variables should be calculated from this first group of 
variables such as energy density or laser spot diameter. The third module includes the modelling tool and is composed of an ensemble of regression trees. Each tree is a model for the process and the ensemble combines the results of these different models in order to improve the model's accuracy. The fourth module generates different plots from the modelling tool that are considered of industrial interest for better prediction of manufacturing strategies and the optimization of process parameters. This module could potentially generate great interest if the soft computing tool were used to extend the use of laser polishing techniques in the mould and die manufacturing industries and could be combined with other optimization strategies [El-Mounayri, 2002].

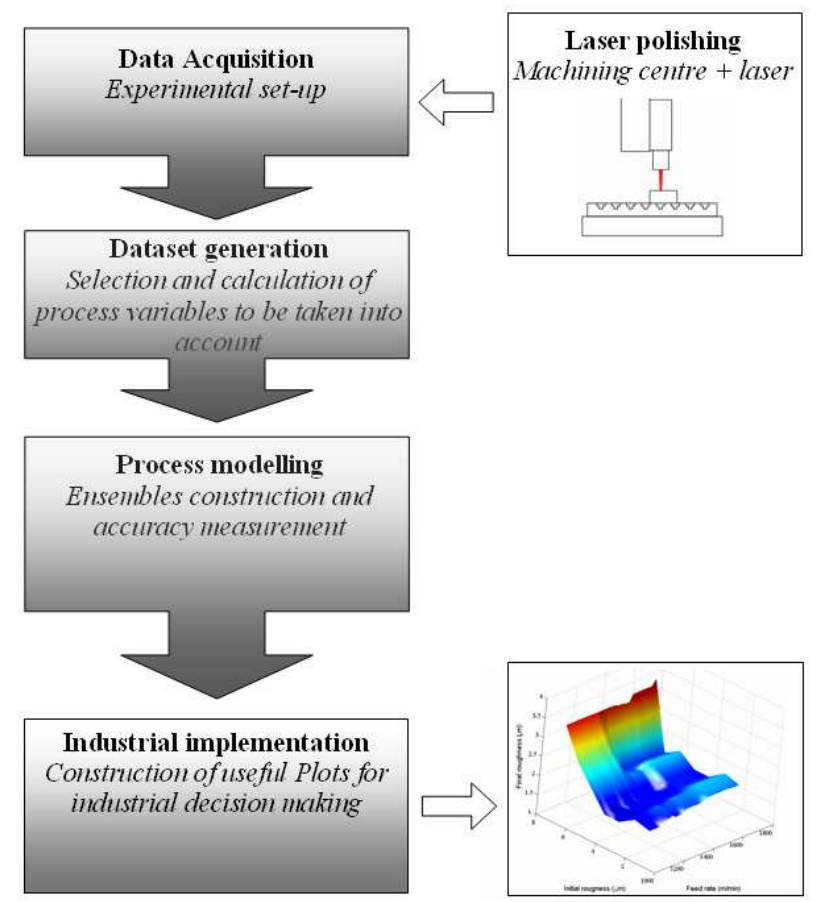

Figure 1. Scheme of the soft computing tool for surface roughness prediction.

This paper is organised as follows. Section 2 introduces the laser polishing fundamentals and the experimental procedure for data collection including the dataset description. Section 3 describes the possibilities of modelling, using Ensembles considering the specific nature of the laser polishing process. Section 4 presents and discusses the experimental results of the measurements and of the modelling using ensembles and the way in which plots can explore potential applications of industrial 
interest that can be obtained from the soft computing tool. Finally, the conclusions are presented and future lines of work are discussed.

\section{Laser Polishing Fundamentals and Experimental Procedure}

The laser polishing process principle is based on a controlled melting of a microscopic surface layer of material using a laser beam as an energy source. Laser polishing processes have been carried out successfully for more than 10 years in the polishing of ceramics [Nicolas, 1997] [Triantafyllidis, 2005] and metals [Henari, 1995]. If the process parameters are optimum, the laser beam will only melt the material of the topography peaks and the melted material then fills the valleys resulting in a smoother topography than the initial one [Ramos-Grez, 2004]. Figure 2 is a schematic representation of the fundamental parts of the process, where a defocused beam is used to melt surface asperities in order to reach smoother topography. Once the material is melted, the attenuation of the asperities is given by several mechanisms such as capillary and gravitational forces, and recoil pressure [Perry, 2009]

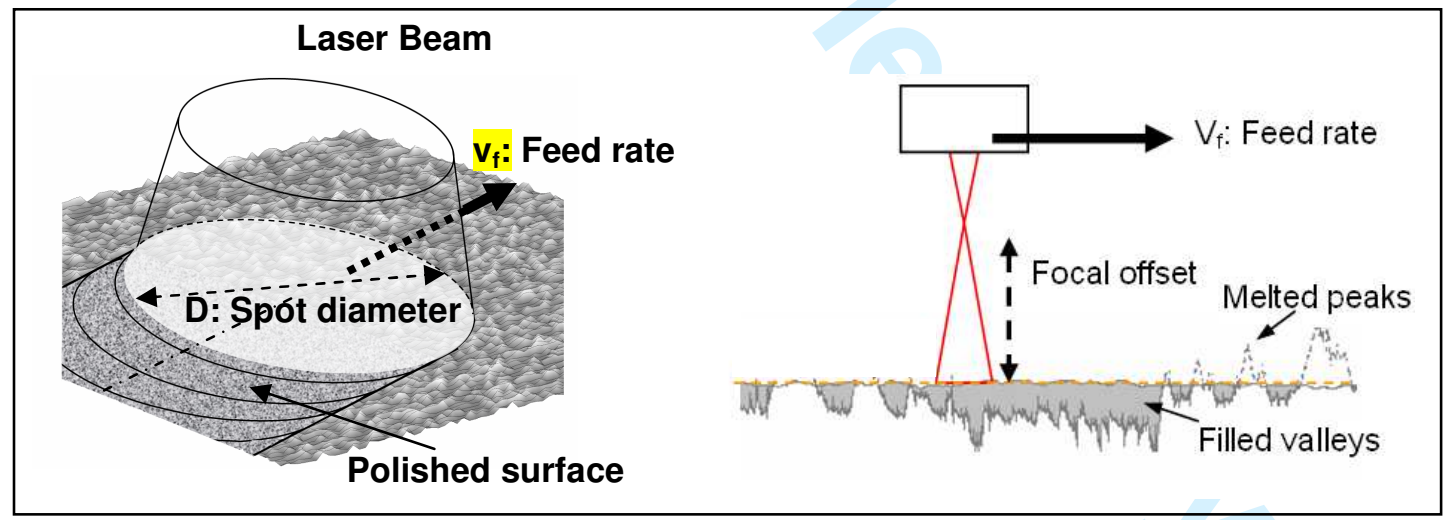

Figure 2. Laser polishing scheme

The process result depends mainly on three factors: the surface material, its initial topography and the energy density of the laser beam. The combination of these factors fixes the amount of melted material. In other words, its thickness depends on the radiated energy density and the material radiated surface topography. Therefore, once the workpiece is manufactured to its final geometry, usually by ball-nose milling, the 
laser process will be successful, if the energy density is correctly selected for the workpiece material and its actual roughness. But, under industrial conditions, not all of these three factors are always known. The surface material usually does not present a problem. The surface topography, in terms of roughness $R_{a}$, can be calculated with a reasonable error in ball-end milling operations [Quintana, 2010]. On the other hand, the energy density (ED), which expresses the energy radiated per surface unit, depends on three process parameters: beam power, radiation time and the spot area. Normally, the theoretical spot size at focal point is known and depends on the optic and laser types in use. However, real spot size in laser polishing processes varies significantly with focal offset distance and the beam incidence angle [Gutu, 2002].

Equation 1 represents the relationship between energy density and the focal offset distance when the laser operates in a defocused way. As mentioned, spot size depends also on the angle of incidence and can present some distortions due to surface asperities, which makes it difficult to verify as a parameter when calculating the effective energy density for the polishing process. Radiation time represents the time while the laser is operating at the same point and it is directly controlled by the feed rate when operating in continuous mode $(\mathrm{CW})$, or the pulse duration if the laser operates in pulse mode. One of the most relevant advantages of this process is that it can be implemented on a commercial SLS machine. In this case, the standard example is the CW mode laser and all tests in this work were performed in this mode.

$$
\text { Equation 1. Energy Density } E D=\frac{6000 \cdot P}{V_{f} \cdot D} \quad \text { Where, }\left\{\begin{array}{l}
P=\text { Power }[W] \\
v_{f}=\text { Feed Rate }\left[\frac{\mathrm{mm}}{\mathrm{min}}\right] \\
D=\text { Spot Diameter }[\mathrm{mm}]
\end{array}\right.
$$

Laser power and feed rate can be accurately controlled by the laser generator and the machine. The laser spot diameter depends on two factors: the distance between the material blank and the focus of the laser beam, called the focal offset position, and 
the diameter of the laser spot for every power value. The first factor allows the spot diameter to be easily adjusted by varying the distance between the laser head and the material blank. Figure 3 shows the variation of the $\mathrm{CO}_{2}$ laser spot size used for the laser polishing tests. Several pulses were carried out on a methacrylate test part to measure the spot diameter at different focal offset distances. Then, the spot diameter was obtained by measuring the trace on two perpendicular axes..

But this adjustment does not take the real effective spot diameter into account, which is defined as the diameter of the spot on the surface, as the real spot is not a perfect circumference and is also influenced by incidence angle and surface asperities. It therefore remains an unknown factor for industrial tests.

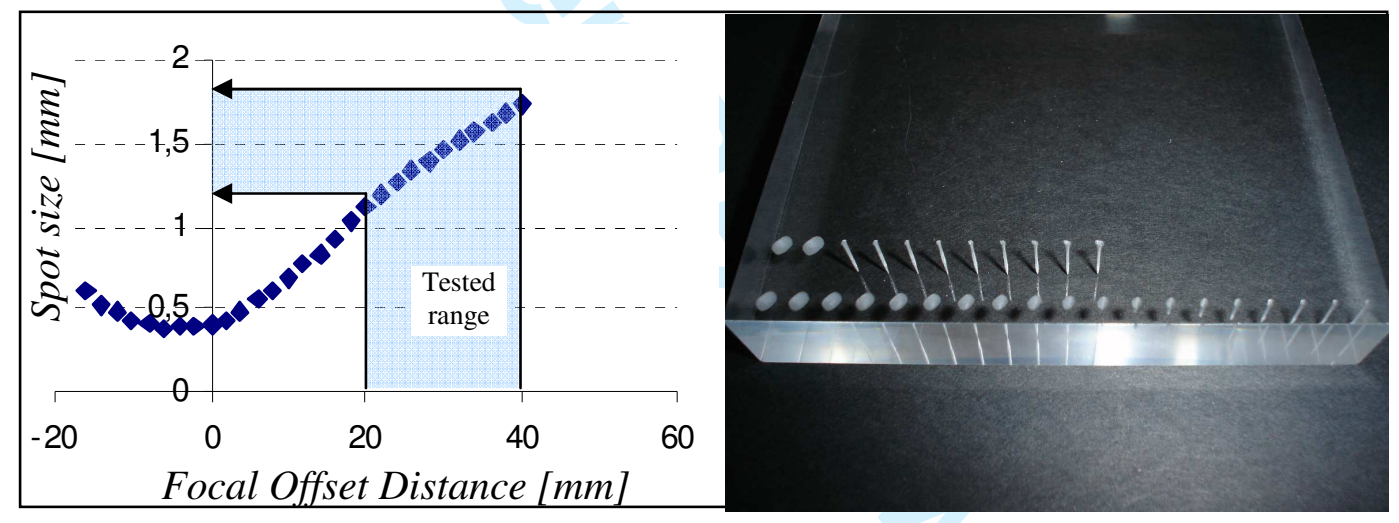

Figure 3. Relationship between spot size and focal offset distance for a fixed laser power

\subsection{Experimental setup}

The experimental objective was to test a broad range of combination process parameters. This broad range should guarantee that all the process parameters are sufficiently varied to provide the soft computing model with sufficient information on its influence in the polishing process. The following two parameters were measured: mean roughness and the reduction rate, calculated as the relationship between the final and the initial roughness. The measurement was carried out in a Taylor Hobson Series 2 profilometer with vertical resolution of $3 \mathrm{~nm}$. The tests consisted of a series of single 
polishing paths of $20 \mathrm{~mm}$ length where mean roughness was measured. In each test, the measurement length was $10 \mathrm{~mm}$, with a Gaussian filter of 2.5 for initial profiles and $0.8 \mathrm{~mm}$ for polished areas. The roughness was measured five times along the scanning direction in each sample, and the final result was obtained by the mean value.

Tests were carried out on two different materials, in order to evaluate the potential of the laser polishing process. A first set of experimental tests was carried out on a commercial alloy LaserForm ${ }^{\mathrm{TM}}$ ST-100. This material is composed of approximately $60 \%$ of sintered AISI 420 stainless steel and $40 \%$ of infiltrated bronze. The parts are built up by SLS and its mechanical and thermal properties are optimum for plastic injection moulding applications. The LaserForm ${ }^{\mathrm{TM}}$ ST-100 parts presented a roughness typically obtained from SLS processes with an initial value near $7 \mu \mathrm{m} \mathrm{R}_{\mathrm{a}}$.

A second set of experimental tests was carried out on Orvar Supreme steel parts. Orvar presents a composition of $5.2 \% \mathrm{Cr}, 1.4 \% \mathrm{Mo}$ and $0.4 \% \mathrm{~V}$. This alloy is typically used in mould manufacturing because of its good mechanical properties at high temperatures, high machinability and good performance when hardened. In conventional die and mould making several machining operations are carried out during the manufacturing process until the final shape is reached. The last finishing operations on complex surfaces, just before polishing, are usually carried out by ball end milling operations with small radial steps in order to reach low peak heights and to scan all surface features of complex parts.

To consider a typical surface after a finishing operation, Orvar Supreme parts were previously milled by a $12 \mathrm{~mm}$ diameter ball end mill with a variable radial step, in order to obtain a typical milling-operation surface finish.

The laser polishing tests for both materials were performed with a $\mathrm{CO}_{2}$ laser head Rofin Sinar DC $025 \mathrm{CO}_{2}$ slab laser. The laser head presents a $2.5 \mathrm{~kW}$ power in 
continuous mode. The resulting laser beam has an almost Gaussian energy distribution with a $0.4 \mathrm{~mm}$ diameter spot. The laser head is installed on a dedicated conventional 3 axis gantry structure controlled by a CNC system. The complete experimental set-up is described in Figure 4.

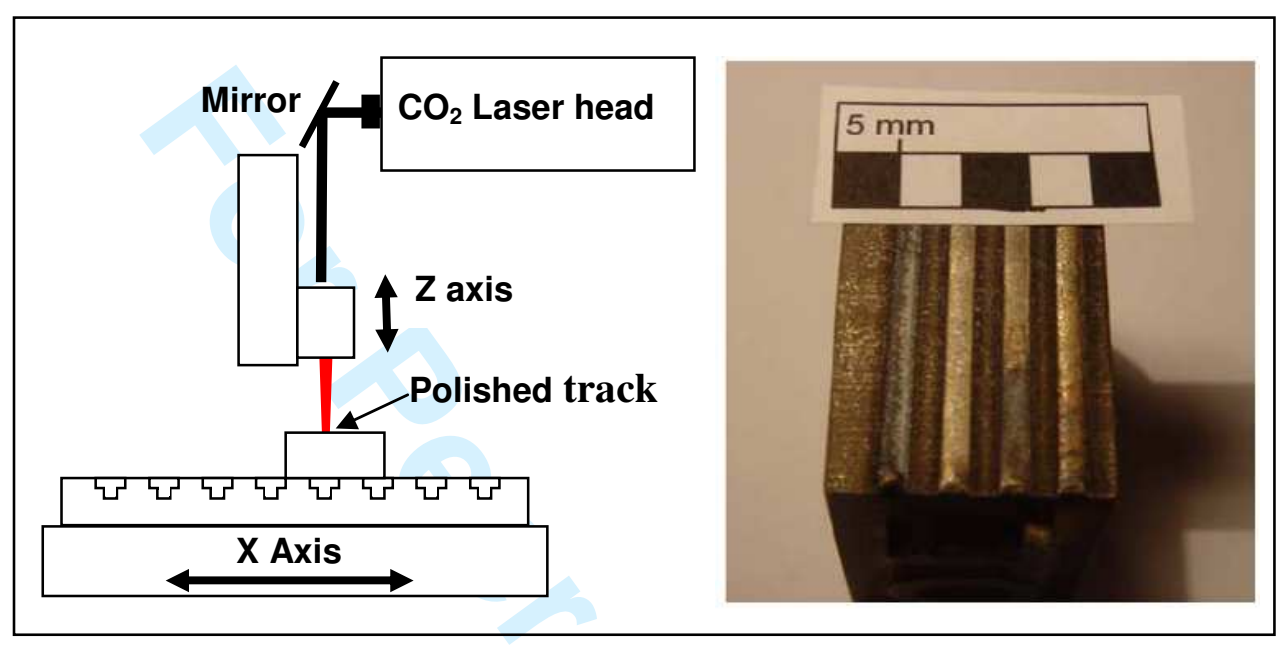

Figure 4: Experimental set-up for the laser polishing test and laser polishing test parts of LaserForm ${ }^{\mathrm{TM}}$ ST-100

\subsection{Laser polishing tests}

Laser polishing test conditions for LaserForm ${ }^{\mathrm{TM}}$ ST-100 were obtained from previous works [Lamikiz, 2007]. These tests demonstrated that the overlap between two consecutive laser tracks when polishing a complete surface was nearly $20 \%$ of the laser beam width. Different energy densities were tested in order to adjust the conditions to the material. The optimum value was set to $360 \mathrm{~J} / \mathrm{cm}^{2}$. Based on these results a new set of single polishing track experiments was developed. The experimentation was developed on the basis of a factorial DoE of three factors at three levels, and includes parameter combinations to get results under and over the optimal value. These are necessary in order to provide the soft computing model with sufficient information on its influence in the polishing process. The DoE was carried out using the commercial software Design Expert $\mathrm{V7}^{\mathrm{TM}}$. 
For Orvar Supreme, prior experimentation was necessary in order to set the minimum and top value for each parameter. In these previous tests, values from [Lamikiz, 2007] were taken as reference and then independently modified to set a range for each parameter including under melting and over melting results. Subsequently, based on same DoE methodology, another set of experiments was carried out to generate the dataset used to feed the ensemble model. Table 1 resumes the parameter values during testing.

Table 1. Process parameter selective for laser polishing tests

\begin{tabular}{|l|c|c|c|c|c|c|}
\cline { 2 - 7 } \multicolumn{1}{c|}{} & \multicolumn{3}{c|}{ LaserForm $^{\mathrm{TM}}$ ST-100 } & \multicolumn{3}{c|}{ Orvar Supreme } \\
\cline { 2 - 8 } \multicolumn{1}{c|}{} & Level 1 & Level 2 & Level 3 & Level 1 & Level 2 & Level 3 \\
\hline Power [W] & 600 & 800 & 1,000 & 1,200 & 1,400 & 1,600 \\
\hline Feed Rate [mm/min] & 1,200 & 1,500 & 1,800 & 1,100 & 1,300 & 1,500 \\
\hline Focal Offset [mm] & 20 & 27 & 34 & 20 & 27.5 & 35 \\
\hline
\end{tabular}

Despite the relevance of the overlap index as a process parameter in the polishing of areas, the study only focused on single polishing tracks in order to limit the number of process variables.

Three different conditions regarding assistance gas were tested. Although the influence of assistance coaxial shielding gas in the laser polishing process is very limited from the point of view of roughness, from an industry-wide perspective, the process cost and the physical properties of the manufactured workpiece can change dramatically with this process parameter. Therefore three conditions were tested: no assistance gas, air, and argon.

\subsection{Dataset generation}

When the experiments were already performed and the roughness of the laser polished blanks had been measured, the dataset for the ensemble model was generated. Among the variables that influence the polishing process, the following were considered: 
material, focal offset distance, spot diameter, laser power, feed rate, energy density, assistance gas, initial roughness and final roughness. Most of these variables were directly measured, as explained in Section 2.1, and only the spot diameter and the energy density weree calculated indirectly. The spot diameter is estimated from a linear fit of the measurements shown in Figure 3. The energy density is calculated from Equation 1, although it has also been explained that it is only an estimate, because the effective laser spot size for the polishing process is not known. Table 2 summarizes the considered variables and their variation range.

Although most of these variables take a limited number of values due to the definition of the experiment, the dataset considers focal offset distance, spot diameter, laser power, feed rate, energy density, initial roughness and final roughness as continuous variables. Other variables, such as material and assistance gas are considered categorical variables: the material takes only two possible values and assistance gas three, see Table 2 . 
Table 2. Variables, units and ranges used during the experiments.

\begin{tabular}{|l|cc|}
\hline \multicolumn{1}{|c|}{ Variable (Units) } & Input / Output & Range \\
\hline Material & Input variable & 1 Orvar, 2 LaserForm \\
\hline $\begin{array}{l}\text { Focal offset distance } \\
(\mathbf{m m})\end{array}$ & Input variable & $20-35$ \\
\hline Spot diameter $(\mathbf{m m})$ & Input variable & $1.1-1.9$ \\
\hline Laser Power $(\mathbf{W})$ & Input variable & $600-1,600$ \\
\hline Feed rate $(\mathbf{m m} / \mathbf{m i n})$ & Input variable & $1,100-1,800$ \\
\hline Energy density $\left(\mathbf{J} / \mathbf{m m}^{2}\right)$ & Input variable & $10.5-81.5$ \\
\hline Assistance gas & Input variable & 0 none, 1 Argon, 2 Air \\
\hline Initial roughness $(\boldsymbol{\mu m})$ & Input variable & $1.0-6.8$ \\
\hline Final roughness $(\mu \mathrm{m})$ & Output variable & $0.2-6.2$ \\
\hline
\end{tabular}

\section{Modelling Using Ensembles}

Laser polishing under industrial conditions is a complex multivariable process, in which a clear definition of the main variables that define the output roughness of a polished workpiece is not always easy. This conclusion is clearly demonstrated in Figure 5, which collects the scatter plots for each predictive variable and the output. There is no obvious relation between these variables and the output. Therefore it is necessary to explore a suitable method to model the final roughness form from extensive process input variables. 

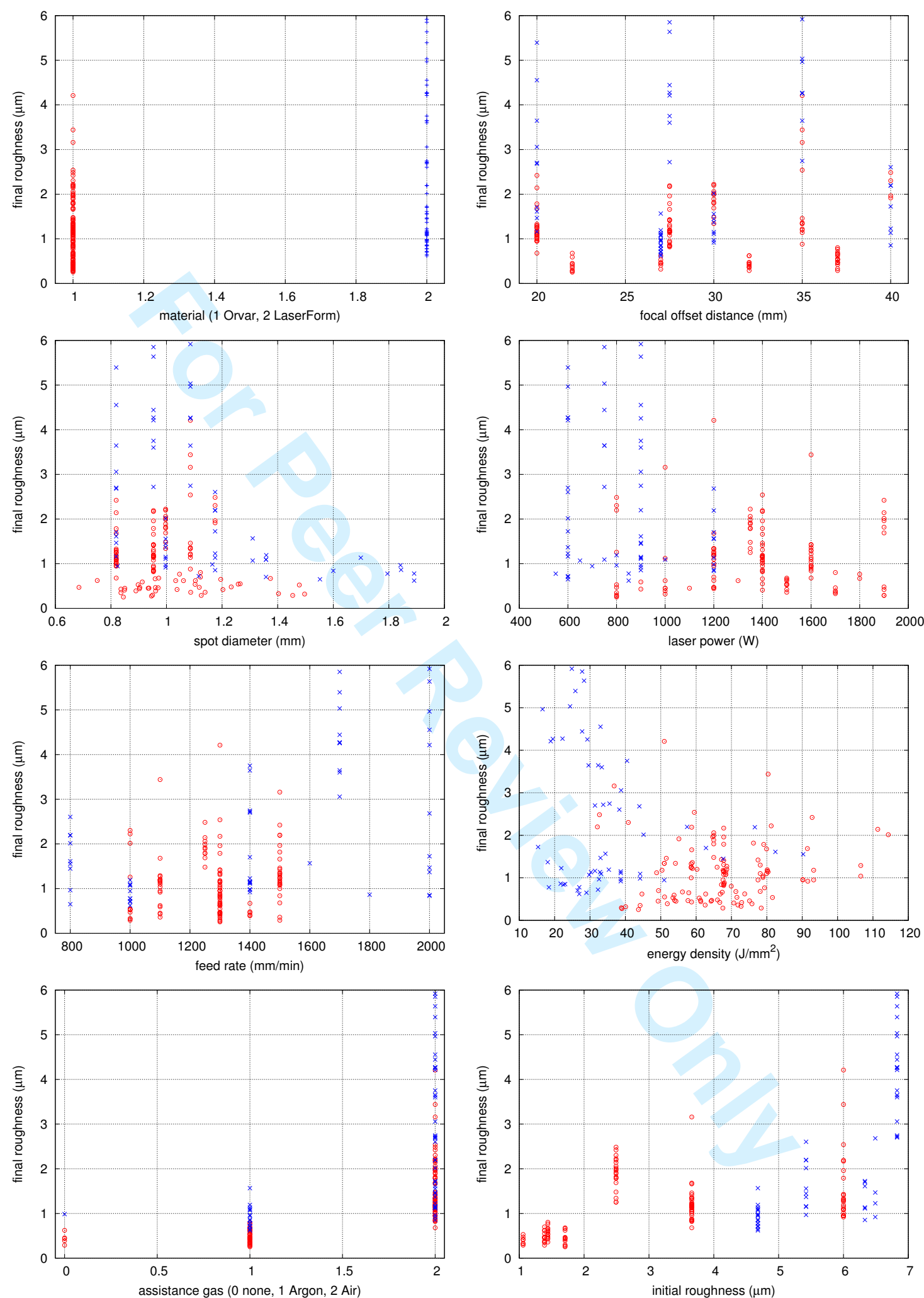

Figure 5. Scatter plots for each predictive variable and the output. The two materials are represented with a different mark. 
There are a multitude of methods that construct models for predicting an output variable from other variables. Instead of selecting a single method, several methods could be selected. A model could be constructed for each method and the predictions combined in some way. Ensembles [Cho, 2010] [Du, 2010] are combinations of several methods that can very often improve on the results of single methods.

It is also possible to have homogeneous ensembles, which combine models obtained from a single method. For this it is necessary to obtain different models from the same method, the standard approach to which is to modify the training data in some way.

Bagging [Breiman, 1996] is one of the most widely known homogeneous ensemble methods. Although very simple, it is generally able to improve on the results of any method, combining models obtained from that method. It can be used for classification and regression. Each base model in the ensemble is trained with a different dataset, a sample with replacement from the original training data. The size of samples is the size of the original training data. As the sample is generated with replacement, an instance can be selected several times and in consequence other instances will not appear in the sample. The algorithm can be expressed therefore as,

\section{Bagging algorithm (for regression)}

Input: Training set $S=\left\{\left(\mathbf{x}_{1}, y_{1}\right), \ldots,\left(\mathbf{x}_{n}, y_{n}\right)\right\}$, base learning algorithm $\boldsymbol{L}$, ensemble size $T$

Output: The final model $M(\mathbf{x})=\sum_{t=1 . . n} M_{t}(\mathbf{x}) / n$

$$
\text { for } t \leftarrow 1 \text { to } T \text { do }
$$

$S_{t} \leftarrow$ bootstrap sample from $\mathrm{S}$

$$
M_{t} \leftarrow \boldsymbol{L}\left(S_{t}\right)
$$

Ensembles can combine models obtained with any method. In this work ensembles that combine only Regression Trees were used. As base models, they have 
some advantages: they can be constructed quickly, are fast predicting and unstable [Breiman, 1996]. The last property means that with small changes in the data set, the obtained models can be very different. It is desirable, for ensembles, because base model diversity is necessary for successful ensembles [Brown, 2006]. Combining identical models is not useful.

As an example, Figure 6 shows a Regression Tree for the problem under consideration. The tree is evaluated top-down. First, at the root node, the value of the initial roughness is compared with 6.66. If it is smaller, the evaluation goes to the left child, otherwise it goes to the right child. In the left child, the assistant gas is compared with 1.5; in the right child, the energy density is compared with 28.79 . This process continues until a leaf node is reached. Every leaf has an associated number, which is the prediction given by the tree when arriving at that leaf. For instance, the leftmost leaf predicts a final roughness value of 0.49 .

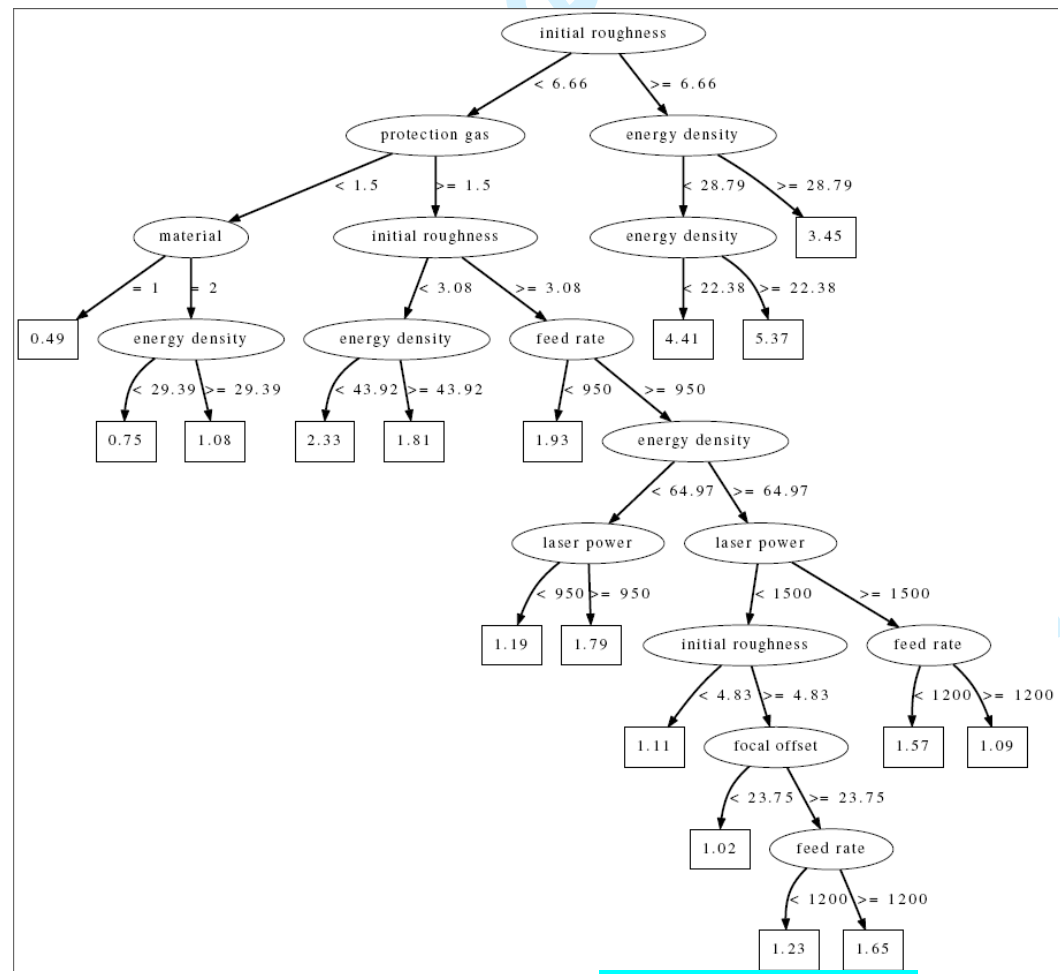

Figure 6. A Regression Tree for this case of study 


\section{Results and Discussion}

\subsection{Measurements Results}

Figure 7 shows the initial roughness profile and polished profile for both materials

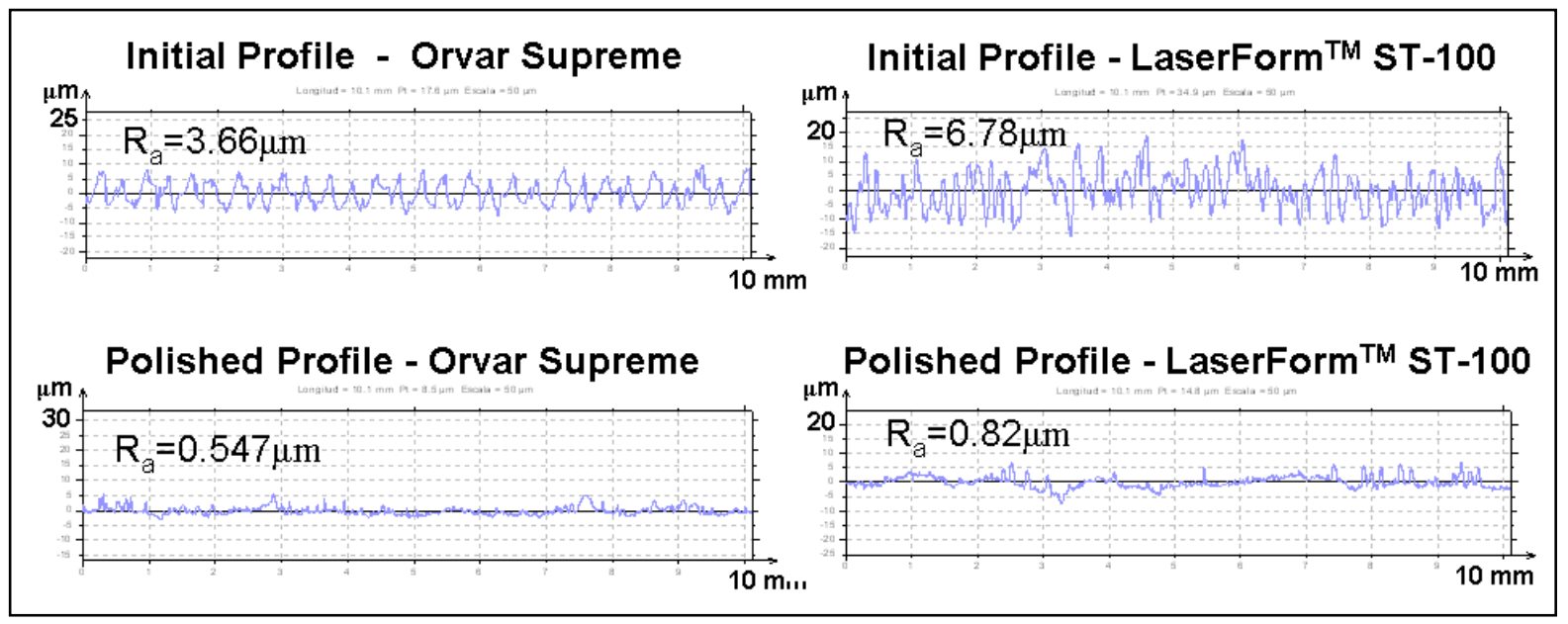

Figure 7: Initial and final roughness profiles for Orvar Supreme (left) and LaserForm ${ }^{\mathrm{TM}}$ ST-100 (right)

In laser polishing, when surface asperities progressively melt, the roughness reduction reached will increase with the energy density up to a limit point. From that point, as energy density increases, the roughness reduction will decrease [Ukar, 2010]. This behaviour corresponds to the melted layer thickness; if the melted layer depth approximates to the surface peak-valley distance, the maximum roughness reduction rates are obtained. If the melted layer depth is clearly higher than the peak-valley distance, a wavy surface appears because of convective currents in the melt pool.

In the tests, when a direct relation between the focal offset and spot diameter was considered to obtain the energy density $(1.122 \mathrm{~mm}, 1.37 \mathrm{~mm}$ and $1.567 \mathrm{~mm}$ diameter for $20 \mathrm{~mm}, 27 \mathrm{~mm}$ and $34 \mathrm{~mm}$ focal offset), the roughness reduction increased up to a limit value, as expected, but there was considerable dispersion between values as can be seen in Figure 8. This may be explained because of the uncertainty between the theoretical and the real effective spot size for the laser polishing process. This difference is due to the influence of the incidence angle and laser power on the effective spot size 
as explained previously in Section 2. The result for Orvar Supreme presented lower dispersion and its evolution can be appreciated more clearly. Maximum roughness reduction rates were obtained for very different energy density rates: while for LaserForm $^{\mathrm{TM}}$ ST-100 the maximum reduction was obtained for energy densities of $3,000 \mathrm{~J} / \mathrm{cm}^{2}$, for Orvar Supreme the maximum was reached near $5,000 \mathrm{~J} / \mathrm{cm}^{2}$. This fact can be explained by the different melting temperature of each material and the initial peak-valley distance in each surface.

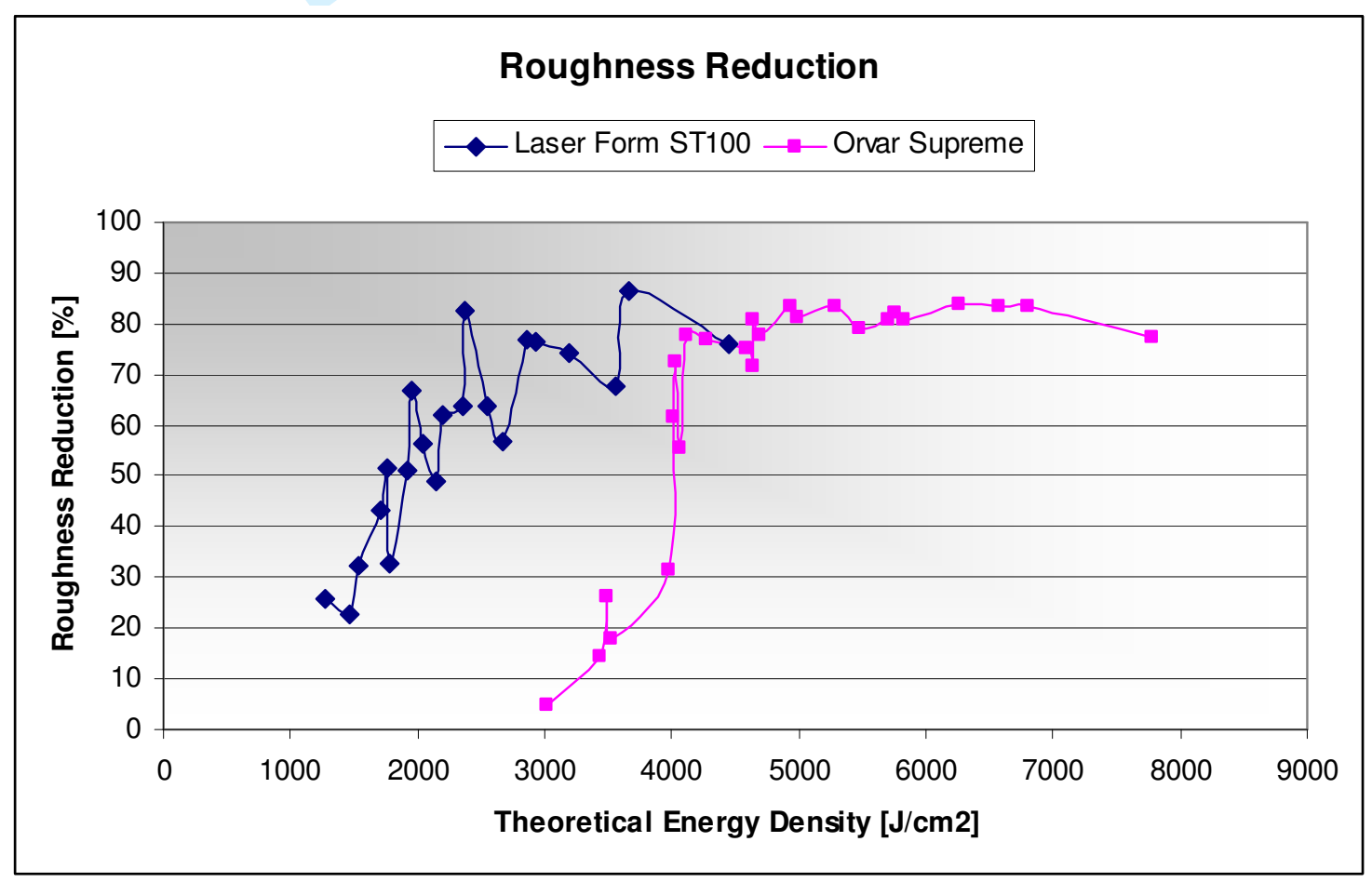

Figure 8. Measured roughness reduction for different theoretical energy densities in LaserForm ${ }^{\mathrm{TM}}$ ST-100 and Orvar Supreme steel

The experimental tests show that a similar evolution of roughness reduction took place in both materials, reaching maximum roughness reductions of almost $80 \%$ of the initial values in both materials. In addition, the maximum reduction is obtained with different energy densities for each material, which can be explained due to their different melting temperature. 


\subsection{Results of Modelling Techniques}

In this section, we compare the performance of base classifiers with the constructed ensembles. The results were obtained using 10-fold cross-validation, repeated 10 times [Cho, 2010]. In 10-fold cross-validation, the data is divided into 10 folds. For each fold, a model is constructed using the other 9 folds and the model is evaluated on the selected fold. The estimation obtained with cross-validation is the average of 10 values, the results for each fold. In order to reduce the variance of this estimation, cross-validation is repeated 10 times, averaging the results obtained from each cross-validation. In other words, the estimations are the average results of 100 models.

Weka (Waikato Environment for Knowledge Analysis) [Witten, 2005] was used for modelling and validation as it contains implementations for each method under consideration.

The ensemble was formed of 100 Regression Trees. It is compared with other methods that are not ensembles: a single Regression Tree, Linear Regression, Multilayer Perceptron, RBF (Radial Basis Function) Network, Nearest Neighbour and Support Vector Machines. For the parameters, the default options in Weka were used, with the following exceptions:

- Pruning was disabled for regression trees. The objective of pruning is to avoid overfitting, but for this problem the results are better with unpruned trees. Moreover, in Bagging the use of unpruned trees is recommended because they are more unstable.

- For the Multilayer Perceptron and RBF Network, the reported results are the best results from 100 architectures, using [1...100] neurons in the hidden layer.

- For Support Vector Machines, the results are reported for the perceptron kernel [Lin, 2008] because it produces better results than the default linear kernel. 
Table 3 presents the results for the different methods under consideration. Three measures were considered: Mean Absolute Error (MAE), Root Mean Squared Error (RMSE) and Correlation Coefficient (CC).

Table 3. Results for the different methods.

\begin{tabular}{|l|c|c|c|}
\hline \multicolumn{1}{|c|}{ Method } & MAE & RMSE & CC \\
\hline Bagging Trees & 0.2948 & 0.4241 & 0.9237 \\
\hline Regression Tree & 0.3391 & 0.4870 & 0.9043 \\
\hline Support Vector Machine & 0.3777 & 0.5825 & 0.8650 \\
\hline Nearest Neighbor & 0.4279 & 0.6597 & 0.8429 \\
\hline Multilayer Perceptron & 0.5260 & 0.7279 & 0.8253 \\
\hline RBF Network & 0.5291 & 0.8039 & 0.7399 \\
\hline Linear Regression & 0.5903 & 0.8411 & 0.7245 \\
\hline
\end{tabular}

Figure 9 reveals the error for Multilayer Perceptron and RBF Network as a function of the number of neurons. The errors obtained with Bagging Trees were much smaller (0.29 instead of 0.52 for MAE, 0.42 instead of 0.72 for RMSE) than the error obtained with these types of Neural Networks, even when selecting the optimal number of neurons in the hidden layer.
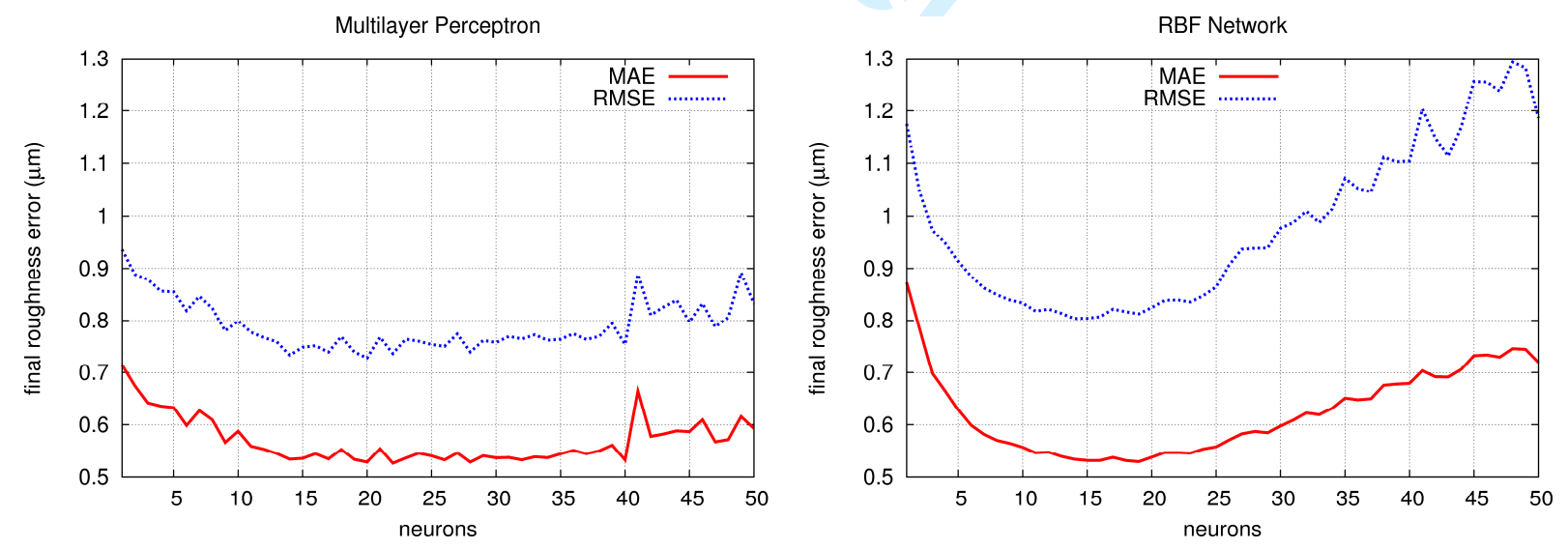

Figure 9. Error for Multilayer Perceptron and RBF network as a function of the number of neurons.

According to the corrected resampled t-test statistic $(\alpha=0.05)$ [Nadeau, 2003], there is a significant difference between the results for Bagging and all the other 
methods, with only one exception. For the Correlation Coefficient in the comparison of Bagging with a single Tree the null hypothesis cannot be rejected. This test was calculated from the 100 results obtained from 10-fold cross-validation repeated 10 times. The correction makes the test more conservative.

Figure 10 shows, for Bagging, the error as a function of the ensemble size. It can be seen that the error from 30 trees is reasonably stable.

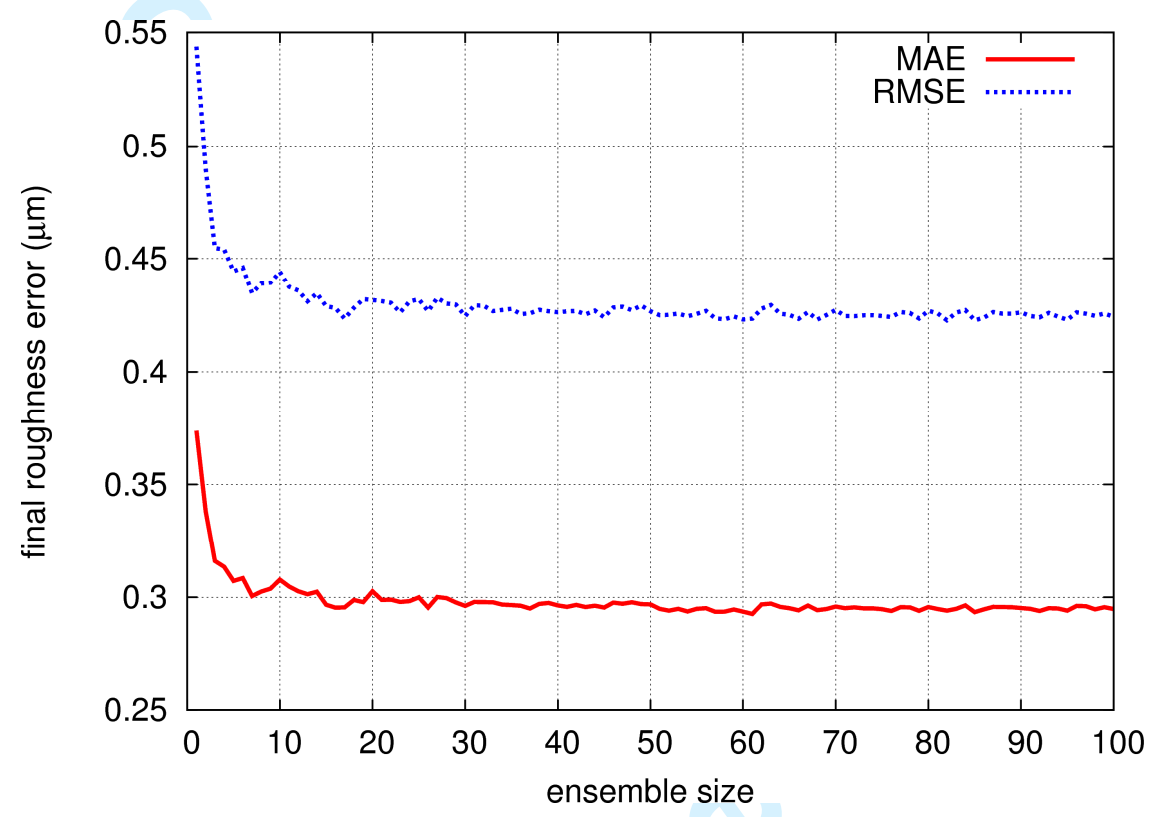

Figure 10. Evolution of the error as a function of the ensemble size.

Figure 11 presents a scatter plot for the actual value of the predicted variable and the average value of the prediction obtained with Bagging. These averages are from 10 values, because cross validation is repeated 10 times. 


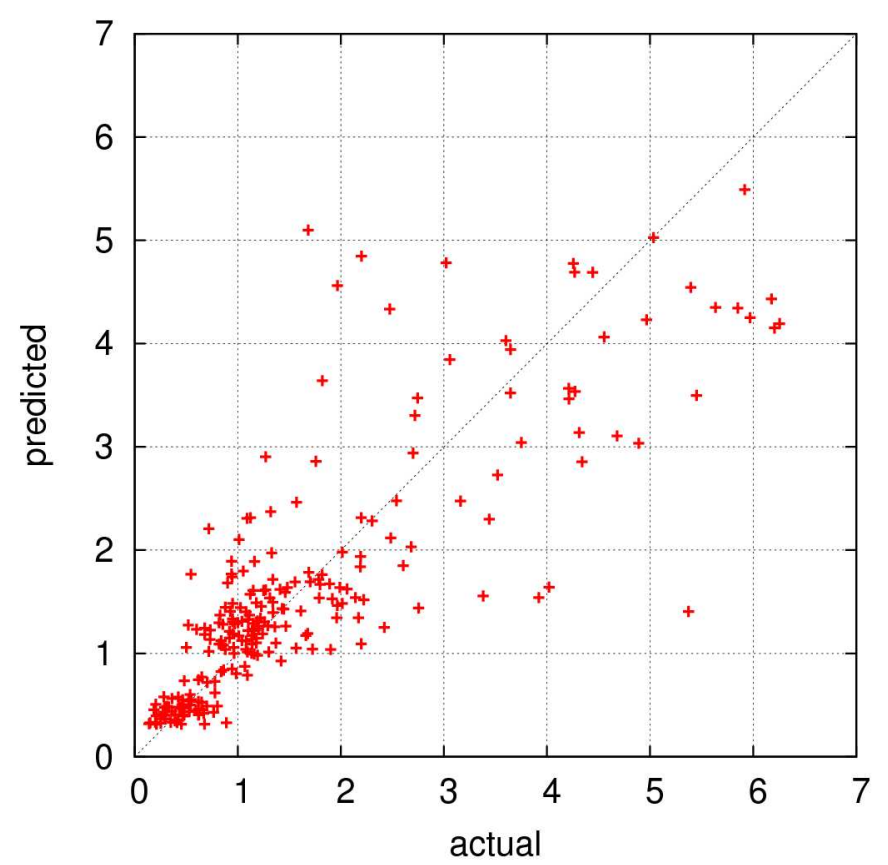

Figure 11. Scatter plot for the actual values and the predicted values of final roughness.

\subsection{Industrial model implementation}

From the industrial point of view, it is not sufficient to demonstrate that the developed soft computing model is accurate enough. It is also necessary to demonstrate that the model can be used under real workshop conditions. Some plots are required to make the information collected in the model useful to any workshop expert. The reality of a manufacturing workshop usually fixes most of the parameters that have been considered in the soft computing model. For example, material and assistance gas is fixed by considering customer requirements. Also, all the laser-spot related parameters such as laser energy density, spot diameter and laser power are fixed to work in a high productivity range. In our case, the model should help the workshop technical office to choose a higher laser polishing feed rate, which would allow a certain final roughness of the workpiece. Also the influence of workpiece roughness before the laser polishing should be considered, because this roughness is mainly defined by the cutting parameters selected for the finishing operation that is completed immediately prior to the polishing operation [Quintana, 2010]. Therefore, it could be of greater interest, from 
an economic or temporal point of view, to improve the quality of this roughness rather than the speed of the laser polishing.

A 3D-plot that represents the final roughness of the workpiece (Z-Axis) as a function of the initial roughness (X-Axis) and the laser polishing feed rate (Y-Axis) has been developed from the soft computing model to facilitate real decision-making in the workshop optimization process. Figure 12 presents this 3D-Plot for the case of Orvar Supreme, focal offset distance of $35 \mathrm{~mm}, 1.53 \mathrm{~mm}$ spot diameter, air as assistance gas and $1,500 \mathrm{~W}$ laser power. It could be clearly observed that with an initial roughness closer to $3.5 \mu \mathrm{m}$, the lower final roughness can be achieved. Also, lower feed rate generates lower final roughness, but this effect is not as strong as the effect of the initial roughness. An immediate decision can be taken to achieve a 3.5-5.5 $\mu \mathrm{m}$ roughness from the milling operations on the workpiece and applied, and then a laser polishing operation at a feed rate of $1,600 \mathrm{~mm} / \mathrm{min}$ to obtain a final roughness of $R_{a} 1-1.5 \mu \mathrm{m}$.

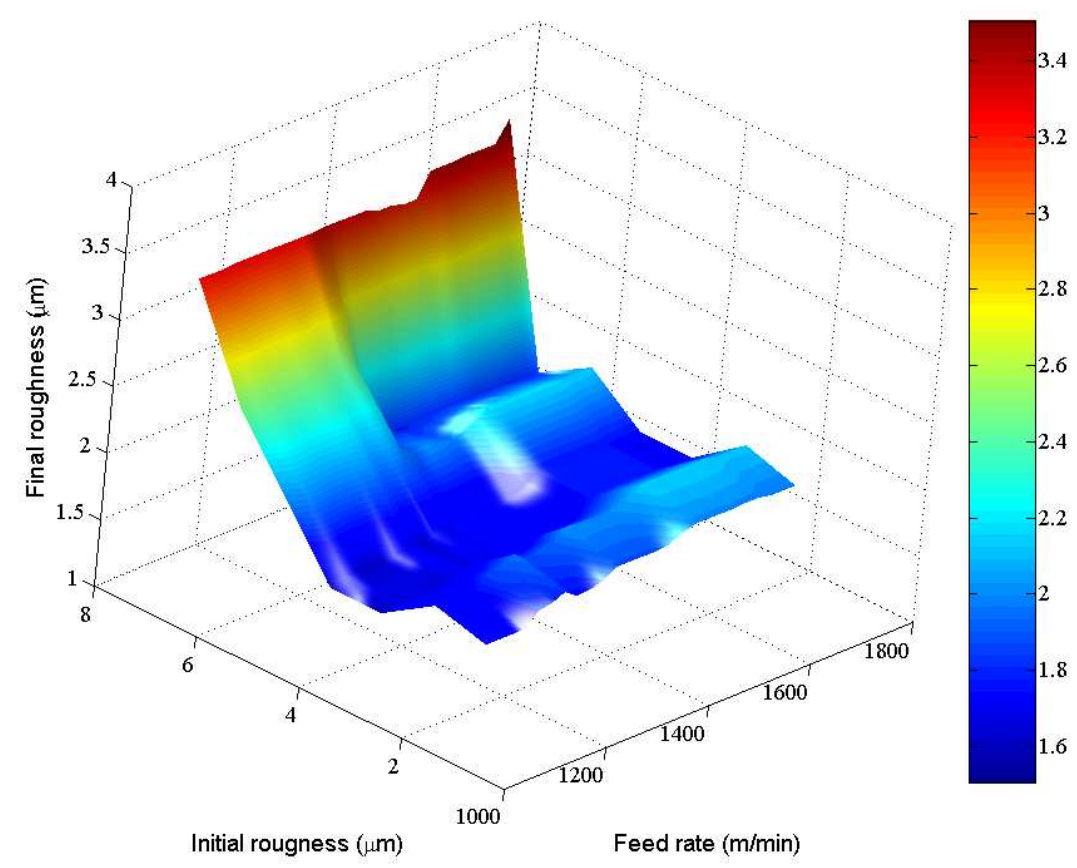

Figure 12. 3D Plot of industrial interest: final roughness as a function of feed rate and initial roughness. 


\section{Conclusions and Future lines of Work}

This research has presented an investigation in order to identify the most appropriate modelling system to solve a real-life industrial problem concerning the laser polishing of metallic components. Several methods were investigated to achieve the best practical solution to this interesting problem. The paper has shown that a fourstep soft computing tool based on modelling, using ensembles of regression trees, is best adapted to this case in terms of identifying the best conditions and predicting future circumstances.

The soft computing tool consisted of 4 modules. The first module collected all the physical information from some the laser polishing process. In order to study the potential of the laser polishing process, a set of experimental tests was carried out on LaserForm $^{\mathrm{TM}}$ ST-100 and Orvar steel, combining different power levels, feed rates, and focal offset distances. Considering a theoretical spot diameter to calculate the density of energy applied, the evolution of the measured roughness reduction in LaserForm ${ }^{\mathrm{TM}} \mathrm{ST}$ 100 presented higher dispersion compared to measurements on Orvar. This fact fits in with the uncertainty of the actual spot size due to the difference of the initial topography for each material tested and the actual spot size.

The second module generated a dataset from the process parameters measured by the first module. This dataset includes variables directly collected from the experiment such as the polished material, spot diameter, laser power, feed rate or initial roughness and other variables that are calculated indirectly such as energy density and the laser spot size.

The third module included the modelling tool and was composed of an ensemble of Regression Trees. Each Regression Tree is a model for the process. The ensemble method was Bagging, and each regression tree was obtained from a different sample from the training data. The accuracy of this ensemble was significantly better than the 
accuracies of a single Regression Tree and other, commonly used methods, such as different types of Neural Networks.

The fourth module generated different plots from the modelling tool. They are considered of industrial interest as they could predict better manufacturing strategies and optimize the process parameters. An example of the possibilities of the prediction tool is shown in a 3D plot in Figure 12 where final roughness is plotted against initial roughness and feed rate. With this plot the process engineer can decide whether a smoother final milling is useful before laser polishing or not and the most suitable combination of laser polishing feed rate and initial workpiece roughness for a low final roughness. This type of graphic information, which highlights the potential advantages of soft computing tools and laser polishing techniques, will be of great interest to the mould and die manufacturing industries.

The novelty of the paper lies in the use of ensemble techniques for modelling laser polishing of steel components when the laser spot diameter is unknown, as often happens under industrial conditions. A comparison of ensemble performance against a well-established soft computing technique such as ANNs is also included in order to demonstrate the improvement in accuracy obtained with the new technique. Future work will consider other ensemble methods, using ensembles from other methods instead of regression trees and will study the use of non-homogeneous ensemble models. These ensembles are built by combining different methods, (e.g., SVM and RBF) and could improve final model accuracy. This soft computing tool will also be applied to other types of materials, such as Ti6Al4V and Inconel 718, which are typically used in the aeronautical industry. In addition, future models should include the effect of variables such as overlap index or 3D geometry. 


\section{Acknowledgments}

This research has been partially supported by the SURFACER project (Ref: DPI2010-20317C02-01) funded by the Spanish Ministry of Science and Innovation The authors would also like to thank the manufacturer of components for vehicle interiors, Grupo Antolin Ingeniería, S.A. in the framework of the MAGNO 2008 - 1028.- CENIT project funded by the Spanish Ministry of Science and Innovation.

\section{References}

[Ahn, 2007]

[Ahn, 2009]

[Binsaeid, 2009]

[Breiman, 1996]

[Brinksmeier, 2010]

[Brown, 2006]

[Cho, 2010]

[Ciurana, 2009]

[Du, 2010]
Ahn, D., Kim, H. and Lee, S. 2007, "Fabrication direction optimization to minimize post-machining in layered manufacturing", International Journal of Machine Tools and Manufacture, vol. 47(3-4), pp. 593-606

Ahn, D., Kim, H. and Lee, S. 2009, "Surface roughness prediction using measured data and interpolation in layered manufacturing", Journal of Materials Processing Technology, vol. 209, pp. 664-671.

Binsaeid, S., Asfour, S., Cho, S. and Onar, A. 2009, "Machine ensemble approach for simultaneous detection of transient and gradual abnormalities in end milling using multisensor fusion", Journal of Materials Processing Technology, vol. 209(10), pp. $4728-4738$.

Breiman, L. 1996, "Bagging predictors", Machine Learning, vol. 24(2), pp. 123-140.

Brinksmeier, E., Levy, G., Meyera, D. and Spierings, A.B. 2010,"Surface integrity of selective-laser-melted components", CIRP Annals-Manufacturing Technology, vol.59, pp. 601-606.

Brown, G., Wyatt, J. and Tino, P. 2006, "Managing Diversity in Regression Ensembles", Journal of Machine Learning Research, vol. 6, pp. 1621-1650.

Cho, S., Binsaeid, S. and Asfour, S. 2010, "Design of multisensor fusion-based tool condition monitoring system in end milling", International Journal of Advanced Manufacturing Technology, vol. 46, pp. 681-694.

Ciurana J., Arias G. and Özel T. 2009, "Neural Network Modeling and Particle Swarm Optimization of Process Parameters in Pulsed Laser Micro-Machining of Hardened AISI H13 Steel", Materials and Manufacturing Processes, vol. 24, pp. 358-368

Du, S., Lv, J. and Xi, L. 2010, “An integrated system for on-line intelligent monitoring and identifying process variability and its 
[El-Mounayri, 2002] El-Mounayri, H., Kishawy, H. and Tandon, V. 2002, "Optimized CNC end-milling: a practical approach", International Journal of Computer Integrated Manufacturing, Vol. 15 Issue. 5, pp. 453-470

[Gutu, 2002]

Gutu, I., et Al. 2002, "Surface treatment with linearly polarized laser beam at oblique incidence", Optics \& Laser Technology, vol. 34, pp. 381-388.

[Henari, 1995]

Henari, F.Z. and Blau, W. 1995, "Excimer-laser surface treatment of metals for improved adhesion", Applied Optics, Vol. 34, pp. 581-584.

[Huissoon, 2002] Huissoon, J.P., Ismail, F., Jafari, A. and Bedi, S. 2002, "Automated Polishing of Die Steel Surfaces", International Journal of Advanced Manufacturing Technology, vol. 19, pp. 285-290.

[King, 2003]

King, D. and Tansey, T. 2003, "Rapid tooling: selective laser sintering injection tooling", Journal of Materials Processing Technology, vol. 132, pp. 42-48.

[Kruth, 2004]

Kruth, J.P., Froyen, L., Van Vaerenbergh, J., Mercelis, P., Rombouts, M. and Lauwers, B. 2004, "Selective laser melting of iron-based powder", Journal of Materials Processing

Technology, vol. 149, pp. 616-622.

[Kruth, 2008]

Kruth, J.-P., Yasa, E., Deckers, J., 2008, "Roughness Improvement in Selective Laser Melting", 3rd Int. Conf. PMI, Ghent, Belgium.

[Kumar, 2008] Kumar Dubey, A. and Yadava, V. 2008, "Laser beam machining-A review", International Journal of Machine Tools and Manufacture, vol. 48, pp. 609-628.

[Lamikiz, 2007] Lamikiz, A., Sánchez, J.A., López de Lacalle, L.N. and Arana, J.L. 2007, "Laser polishing of parts built up by selective laser sintering”, International Journal of Machine Tools and Manufacture, vol. 47, pp. 2040-2050.

[Levy, 2003]

Levy, G.N., Schindel, R. and Kruth, J.P. 2003, "Rapid manufacturing and rapid tooling with layer manufacturing (LM) technologies, state of the art and future perspectives", CIRP Annals Manufacturing Technology, vol. 52, Issue:2, pp. 589609. 
[Liao, 2008]

Liao, T., Tang, F., Qu, J. and Blau, P. 2008, "Grinding wheel condition monitoring with boosted minimum distance classifiers", Mechanical Systems and Signal Processing, vol. 22, pp. 217-232.

[Lin, 2008]

Lin, H.-T. and Li, L. 2008, "Support Vector Machinery for Infinite Ensemble Learning", Journal of Machine Learning Research, vol. 9, pp. 285-312.

[Lü, 2001]

Lü, L., Fuh, J. and Wong, Y.S., 2001, "Laser Induced Materials and Process for Rapid Prototyping". Kluwer Academic. Springer; 1 edition (2001).

[Nadeau]

Nadeau, C. and Bengio, Y. 2003, "Inference for the generalization error", Machine Learning, vol. 52 (3), pp. 239281.

[Nicolas, 1997] Nicolas, G., Autric, M., Marine, W. and Shafeev, G.A. 1997, "Laser induced surface modifications on $\mathrm{ZrO}$ ceramics", Applied Surface Science, Vol. 109-110, pp. 289-292.

[ÓDonnchadha, 2004] ÓDonnchadha, B. and Tansey, A. 2004, “A note on rapid metal composite tooling by selective laser sintering", Journal of Materials Processing Technology, vol. 153-154, pp. 28-34.

[Perez, 2010]

[Perry, 2009]

[Quintana, 2010] Quintana, G.; Ribatallada, J. and Ciurana, Q. 2010, "Surface Roughness Generation and Material Removal Rate in Ball End Milling Operations", Materials and Manufacturing Processes, vol. 25 (6), pp. 386-398.

[Ramos-Grez, 2004] Ramos-Grez, J.A. and Bourell, D.L. 2004, "Reducing surface roughness of metallic freeform-fabricated parts using non-tactile finishing methods", International Journal of Materials and Product Technology, vol. 21, pp. 297-316.

[Santos, 2006] Santos, E.C., Masanari, S., Kozo, O. and Tahar, L. 2006, "Rapid manufacturing of metal components by laser forming", International Journal of Machine Tools \& Manufacture, vol. 46, pp. 1459-1468. 
[Shevade, 1999]

[Sriram, 2007]

[Tuck, 2007]

[Ukar, 2010]

[Weiping, 2003]

[Witten, 2005]

[Yousef, 2003]
Shevade, S.K., Keerthi, S.S., Bhattacharyya, C. and Murthy, K.R.K. 1999, "Improvements to the SMO Algorithm for SVM Regression", IEEE Transactions on Neural Networks, vol. 11(5), pp. 1188-1193.

Sriram, S., and Lye, S.W. 2007, "Layer decomposition and constitution modelling for rapid prototyping", International Journal of Computer Integrated Manufacturing, Vol.20 Issue 4, pp. 387-395.

[Subramonian, 2009] Subramonian, S., Brevern, P., El-Tayeb, N. S. M. and Vengkatesh, V.C. 2009, "Modelling of laser processing cut quality by an adaptive network-based fuzzy inference system", Proceedings Of The Institution Of Mechanical Engineers Part CJournal Of Mechanical Engineering Science, vol. 223(10), pp. 2369-2381.

Tuck, C.J., Hague, R.J.M., Ruffo, M., Ransley, M. and Adams, P. 2007, "Rapid manufacturing facilitated customization", International Journal of Computer Integrated Manufacturing, vol. 21, Issue 3, pp.245-258

[Triantafyllidis, 2005] Triantafyllidis, D., Li, L. and Stott, F.H. 2005, “The effects of laser-induced modification of surface roughness of Al2O3-based ceramics on fluid contact angle", Materials Science and Engineering A, Vol. 390, pp. 271-277.

Ukar, E., Lamikiz, A., López de Lacalle, L.N., del Pozo, D. and Arana, J.L. 2010, "Laser polishing of tool steel with CO2 laser and high-power diode laser. International Journal of Machine Tools and Manufacture", vol. 50, pp. 115-125.

Weiping, L. and DuPont, J. N. 2003, "Fabrication of functionally graded $\mathrm{TiC} / \mathrm{Ti}$ composites by Laser Engineered Net Shaping", Scripta Materialia, vol. 48(9), pp. 1337-1342.

Witten, I.H. and Frank, E. 2005, "Data Mining: Practical Machine Learning Tools and Techniques", Morgan Kaufmann, 2nd edn. http://www.cs.waikato.ac.nz/ml/weka

Yousef, B.F., Knopf G.K., Bordatchev, E.V. and Nikumb, S.K., 2003, "Neural network modelling and analysis of the material removal process during laser machining", International Journal of Advance Manufacturing Technology, vol. 22 (1-2), pp. 4153.

[Yu, 2009]
Yu, J., Xi, L. and Zhou, X. 2009, "Identifying source(s) of outof-control signals in multivariate manufacturing processes using selective neural network ensemble", Engineering Applications of Artificial Intelligence, vol. 22, pp. 141-152. 


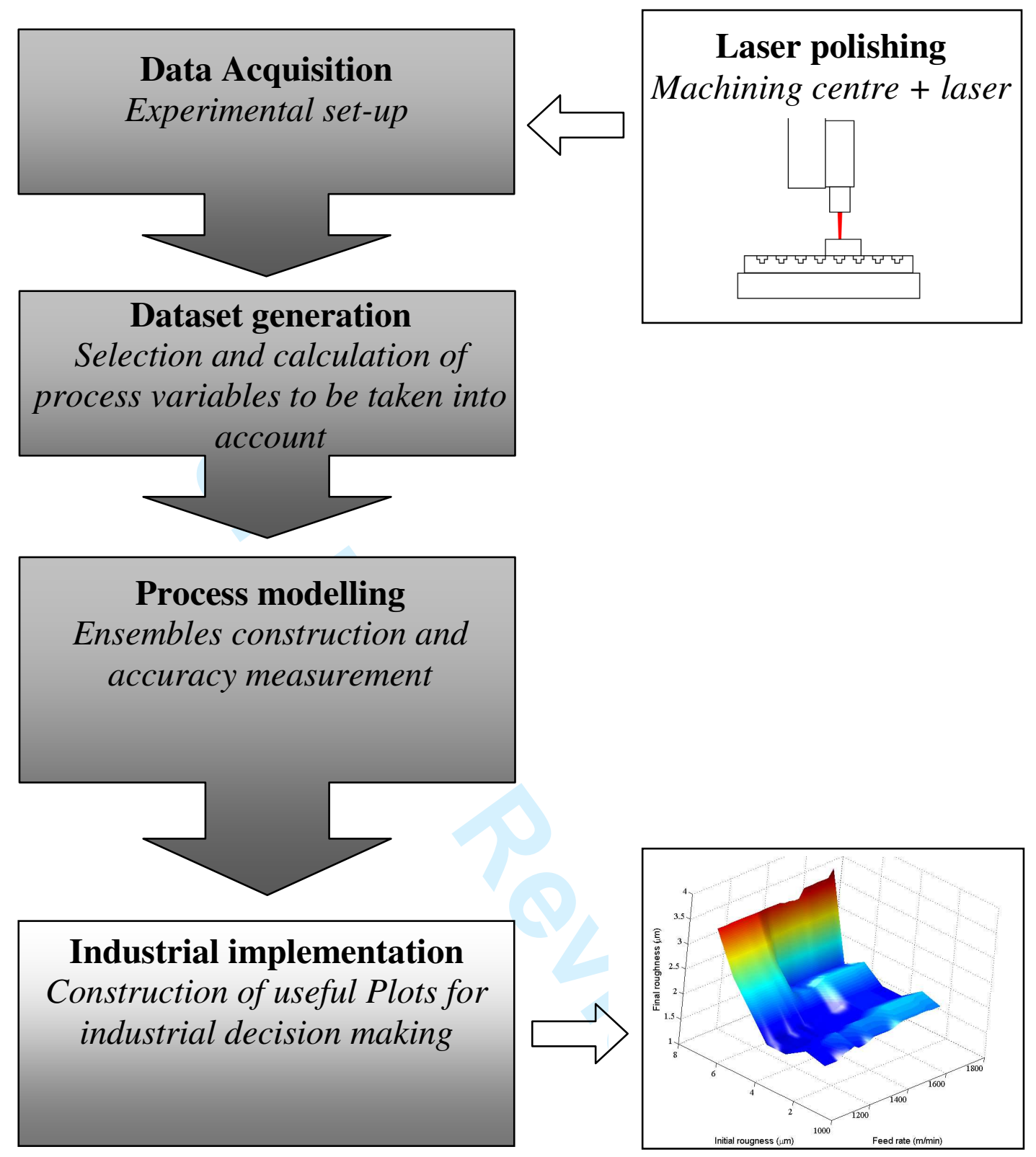

Figure 1. Scheme of the soft computing tool for surface roughness prediction. 

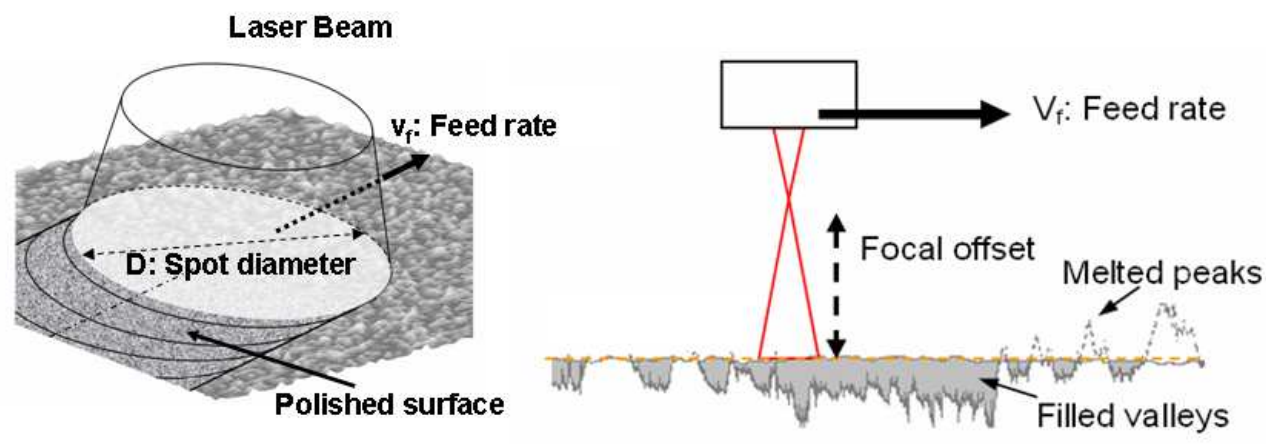

Figure 2. Laser polishing scheme 


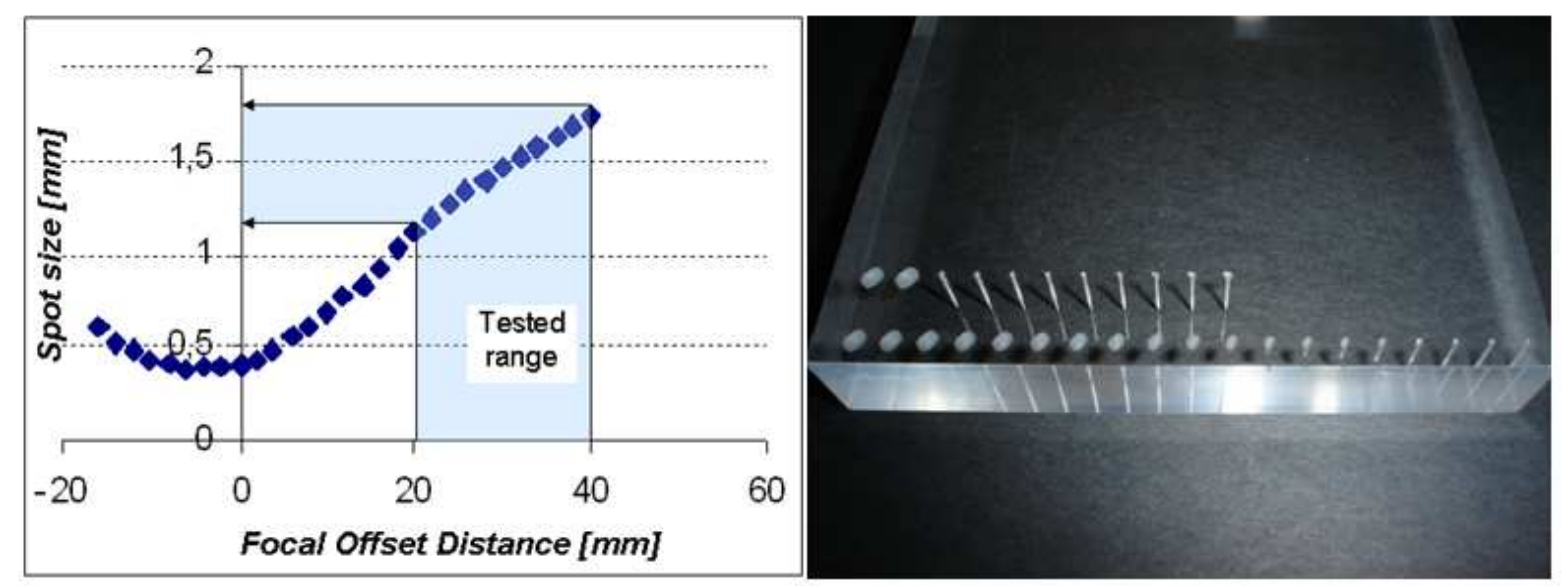

Figure 3. Relationship between spot size and focal offset distance for a fixed laser power 

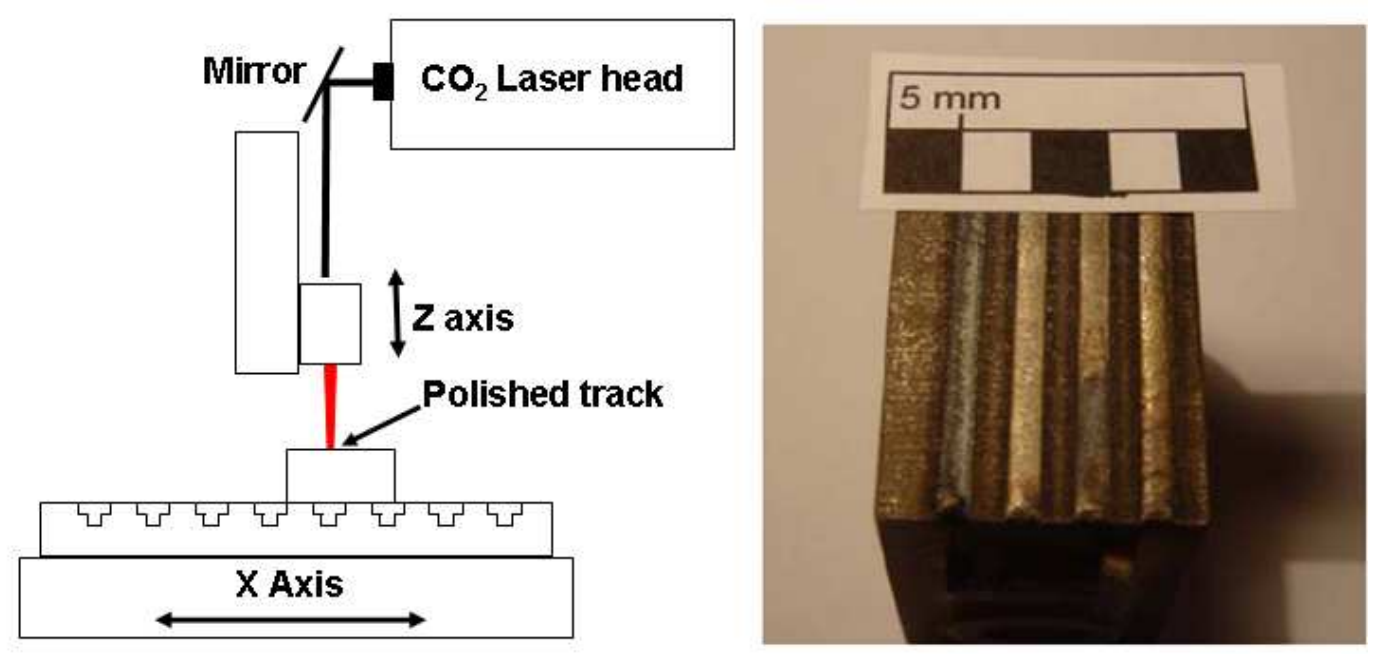

Figure 4: Experimental set-up for the laser polishing test and laser polishing test parts of LaserForm ${ }^{\mathrm{TM}}$ ST-100 

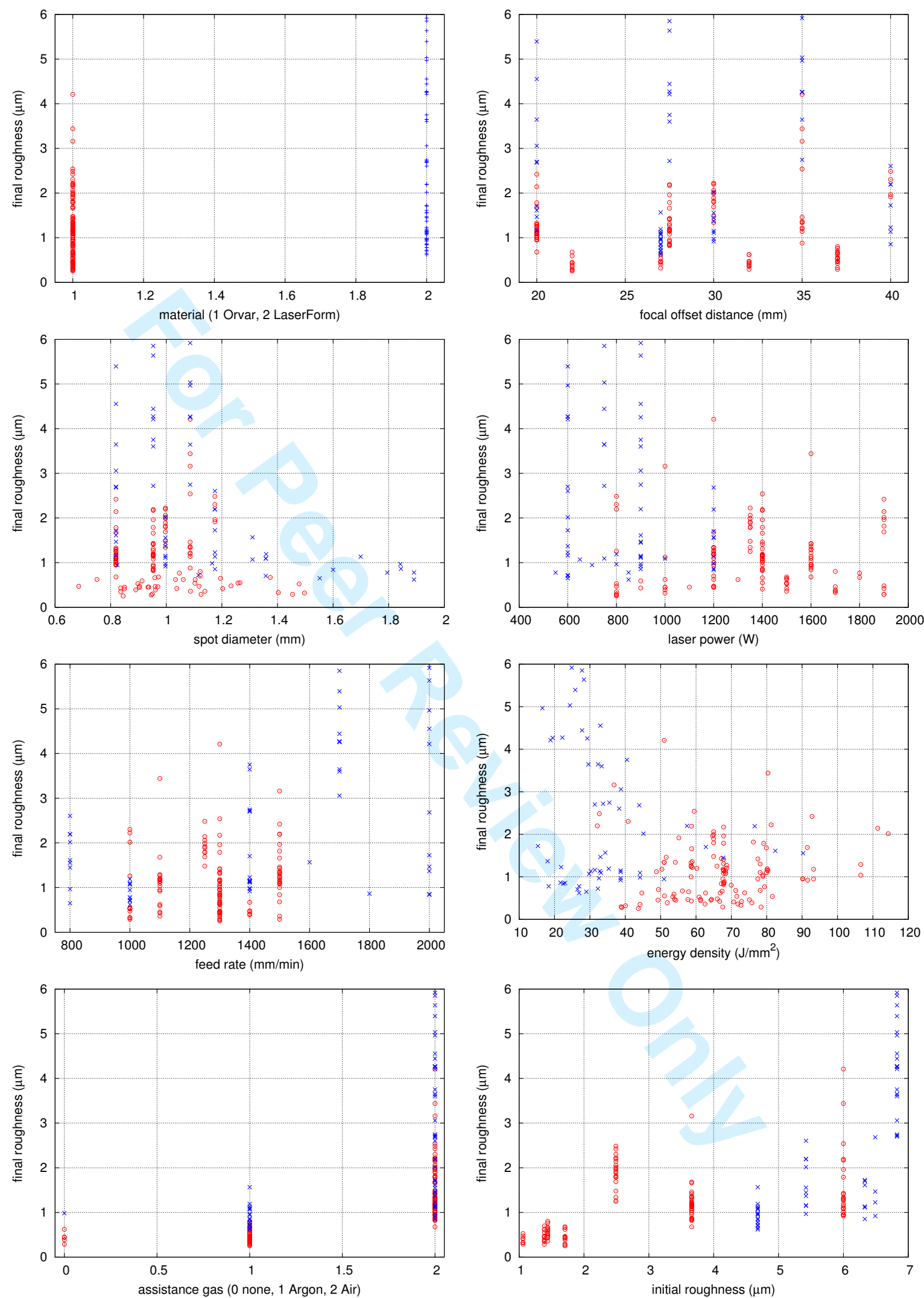

Figure 5. Scatter plots for each predictive variable and the output. The two materials are represented with a different mark. 


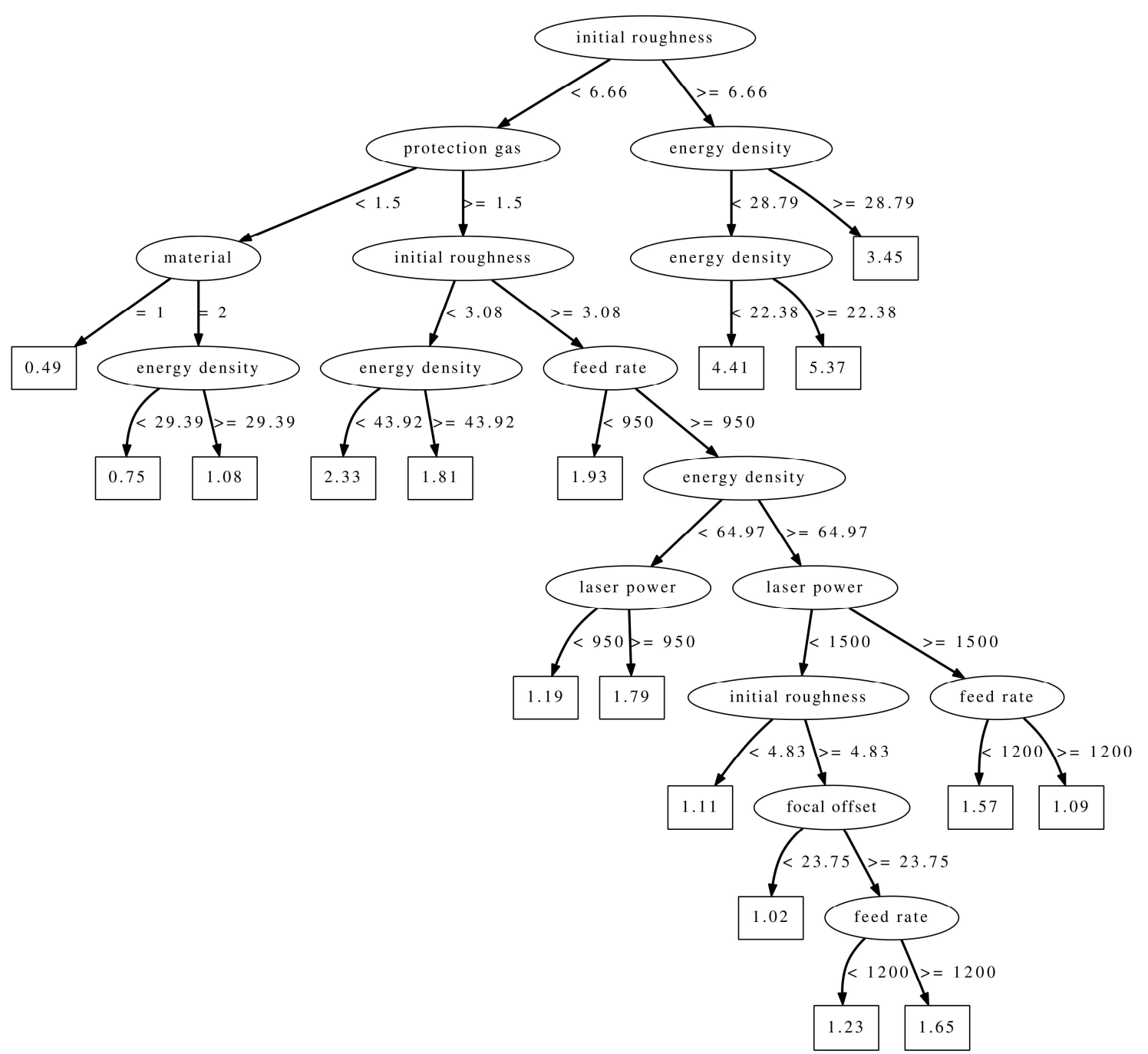

Figure 6. A Regression Tree for this case of study 

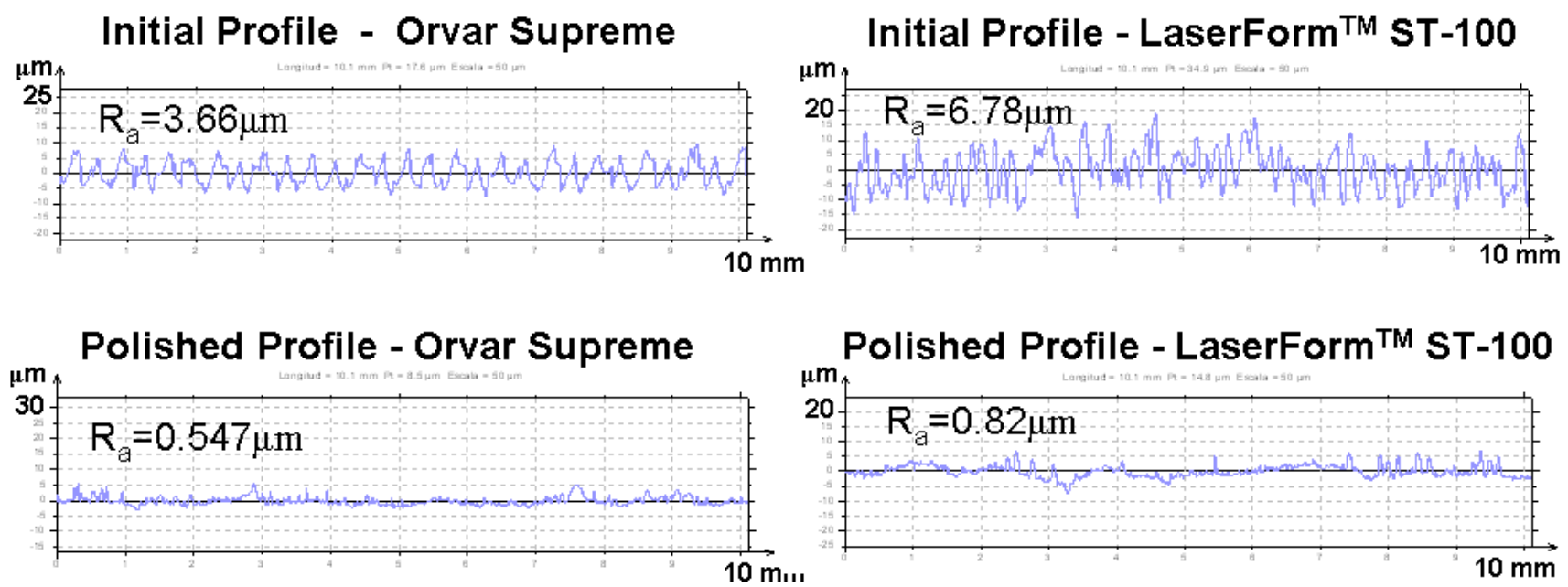

Figure 7: Initial and final roughness profiles for Orvar Supreme (left) and LaserForm ${ }^{\mathrm{TM}}$ ST-100 (right) 


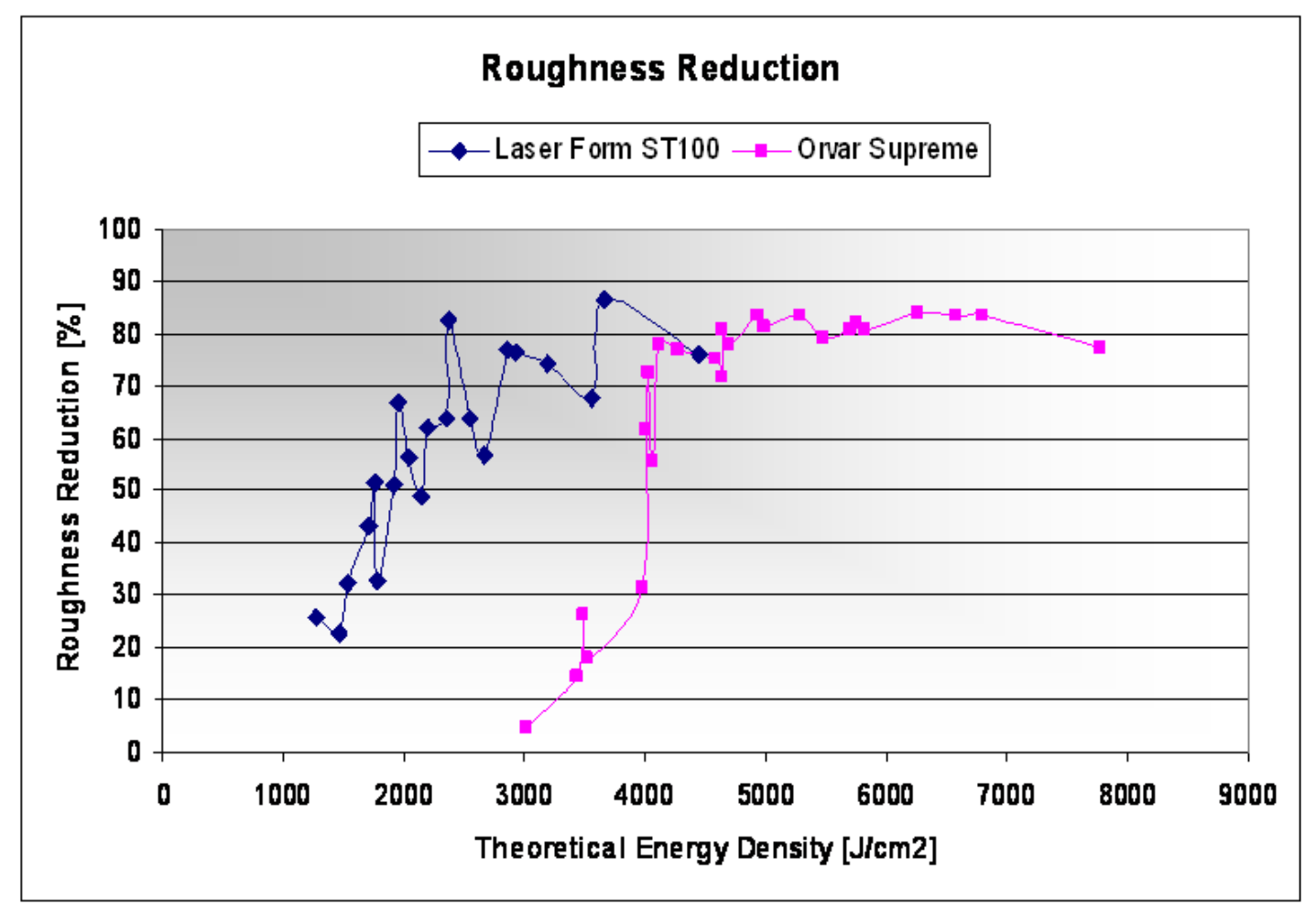

Figure 8. Measured roughness reduction for different theoretical energy densities in LaserForm ${ }^{\mathrm{TM}}$ ST-100 and Orvar Supreme steel 

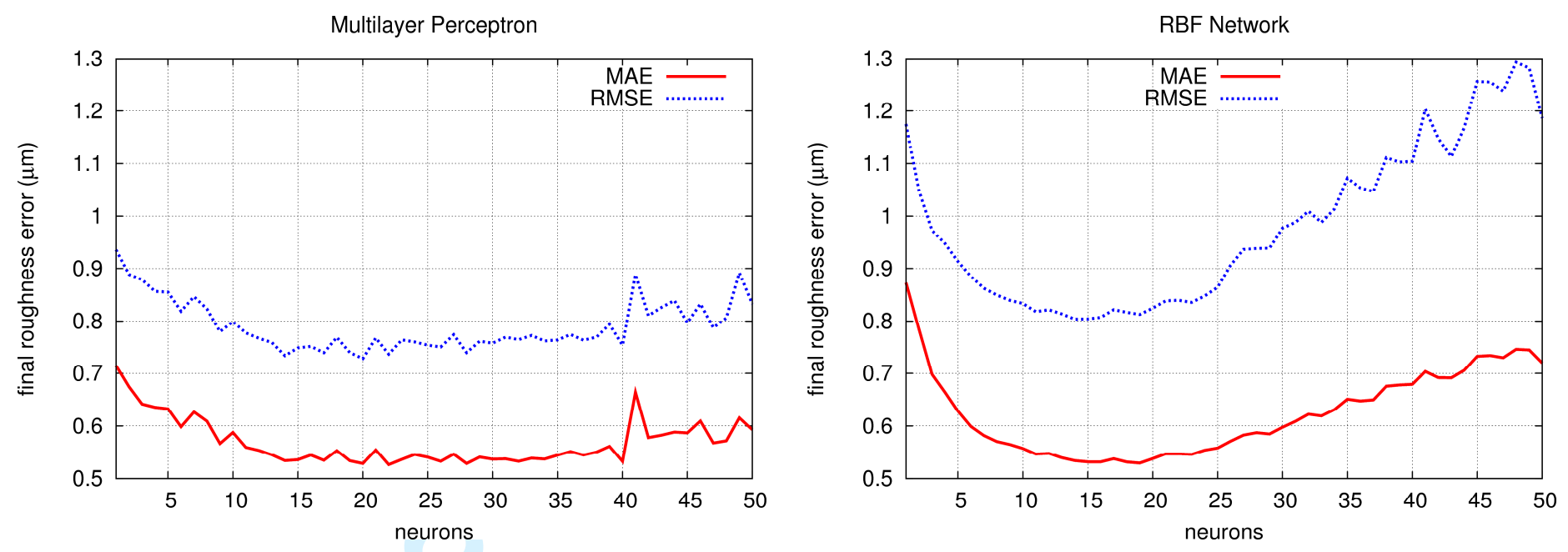

Figure 9. Error for Multilayer Perceptron and RBF network as a function of the number of neurons. 


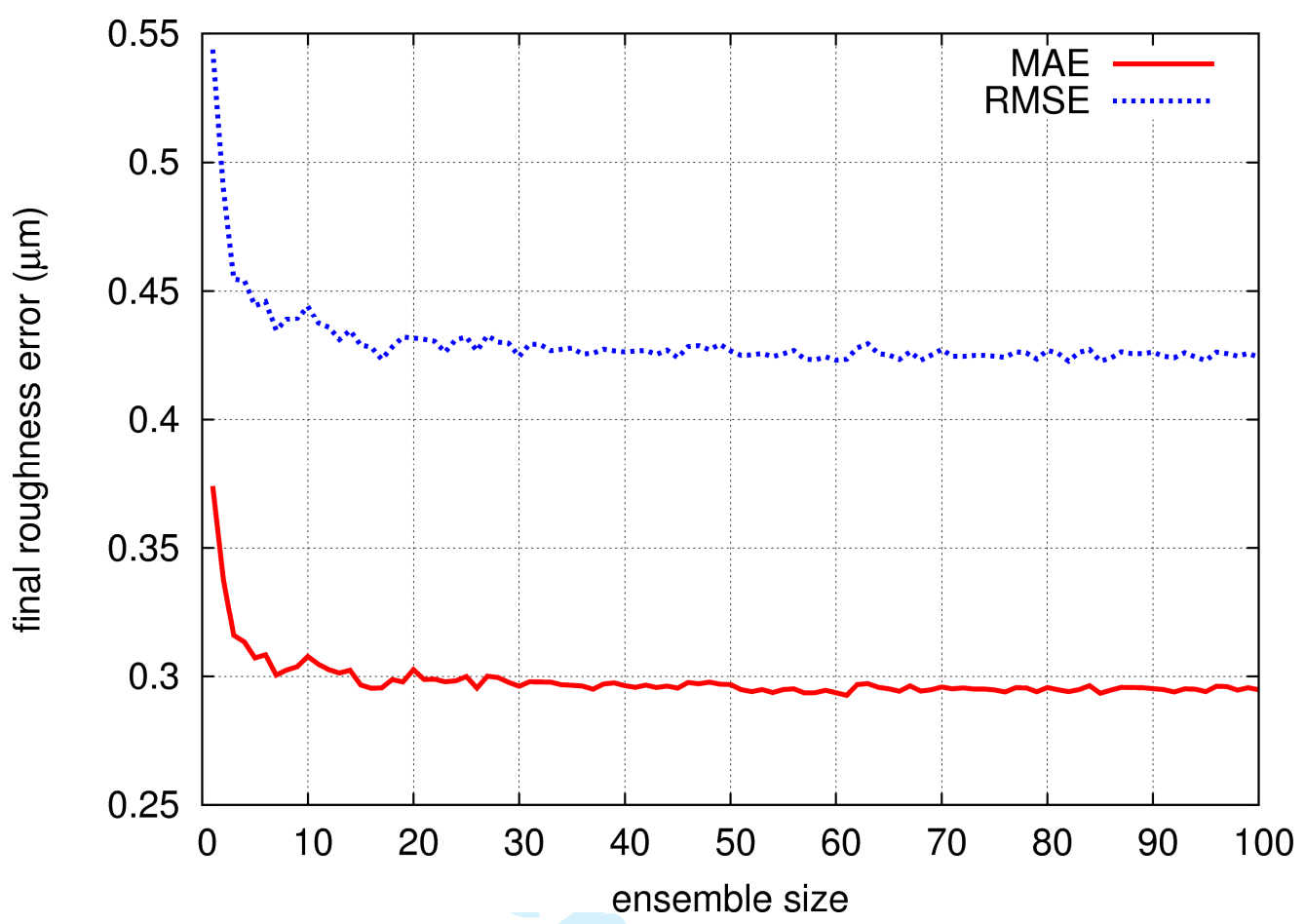

Figure 10. Evolution of the error as a function of the ensemble size. 


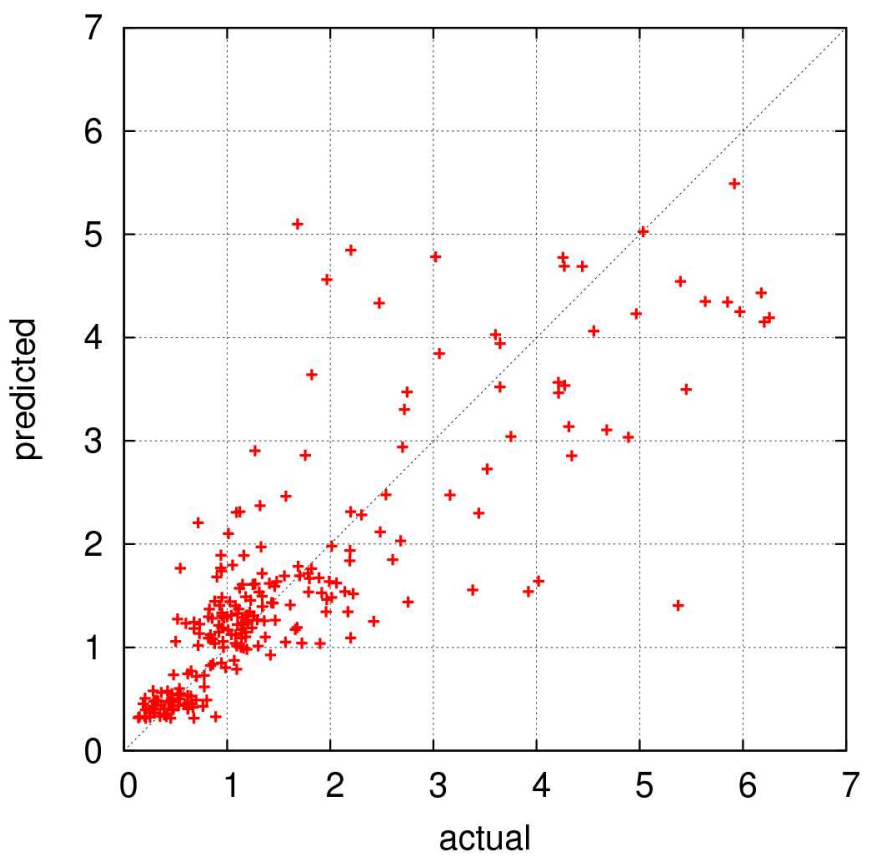

Figure 11. Scatter plot for the actual values and the predicted values of final roughness. 


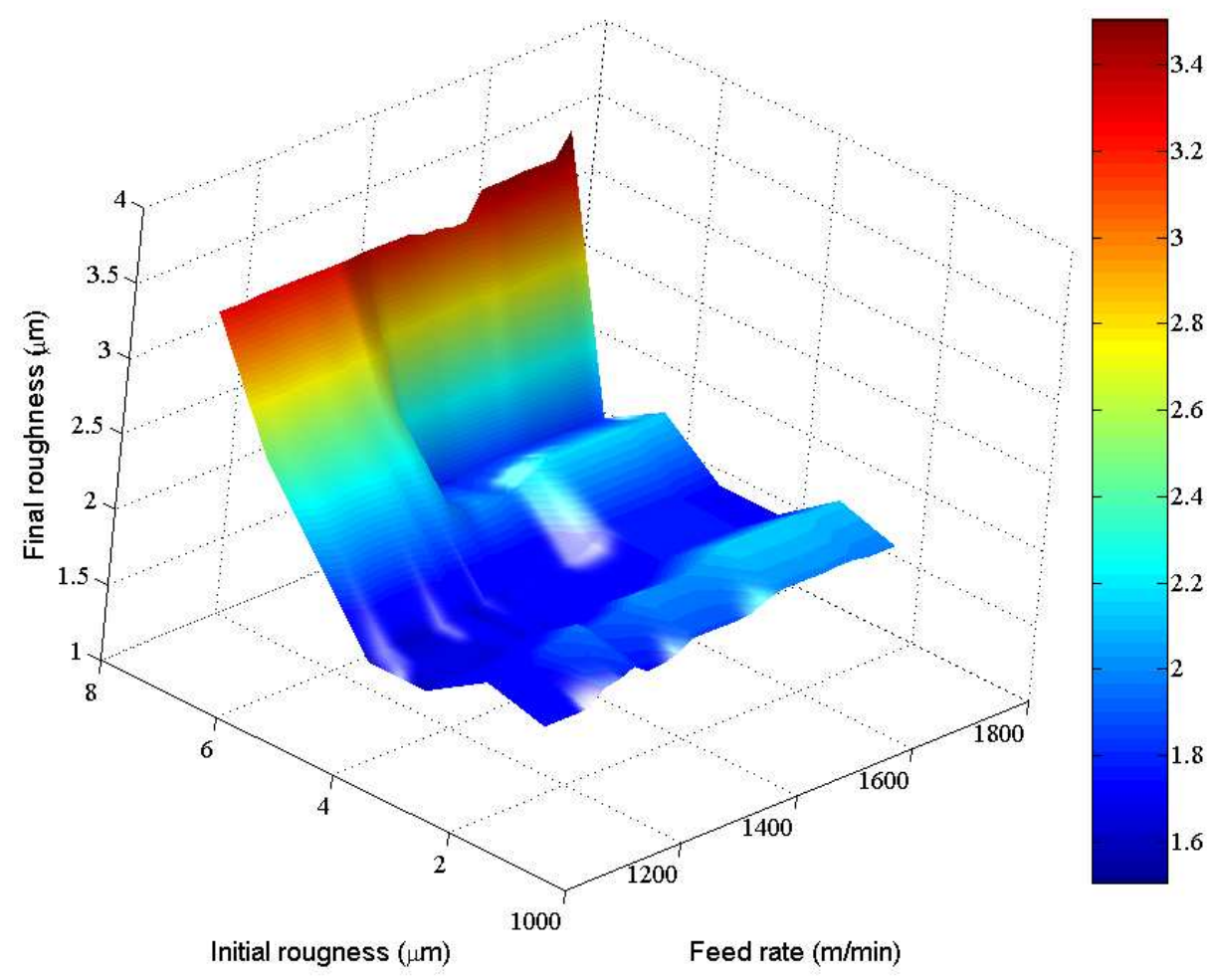

Figure 12. 3D Plot of industrial interest: final roughness as a function of feed rate and initial roughness. 
Table 1. Process parameter selective for laser polishing tests

\begin{tabular}{|l|c|c|c|c|c|c|}
\cline { 2 - 7 } \multicolumn{1}{c|}{} & \multicolumn{3}{c|}{ LaserForm $^{\mathrm{TM}}$ ST-100 } & \multicolumn{3}{c|}{ Orvar Supreme } \\
\cline { 2 - 8 } \multicolumn{1}{c|}{} & Level 1 & Level 2 & Level 3 & Level 1 & Level 2 & Level 3 \\
\hline Power [W] & 600 & 800 & 1,000 & 1,200 & 1,400 & 1,600 \\
\hline Feed Rate [mm/min] & 1,200 & 1,500 & 1,800 & 1,100 & 1,300 & 1,500 \\
\hline Focal Offset [mm] & 20 & 27 & 34 & 20 & 27.5 & 35 \\
\hline
\end{tabular}


Table 2. Variables, units and ranges used during the experiments.

\begin{tabular}{|l|cc|}
\hline \multicolumn{1}{|c|}{ Variable (Units) } & Input / Output & Range \\
\hline Material & Input variable & 1 Orvar, 2 LaserForm \\
\hline $\begin{array}{l}\text { Focal offset distance } \\
(\mathrm{mm})\end{array}$ & Input variable & $20-35$ \\
\hline Spot diameter $(\mathrm{mm})$ & Input variable & $1.1-1.9$ \\
\hline Laser Power $(\mathrm{W})$ & Input variable & $600-1,600$ \\
\hline Feed rate $(\mathrm{mm} / \mathrm{min})$ & Input variable & $1,100-1,800$ \\
\hline Energy density $\left(\mathrm{J} / \mathrm{mm}^{2}\right)$ & Input variable & $10.5-81.5$ \\
\hline Assistance gas & Input variable & 0 none, 1 Argon, 2 Air \\
\hline Initial roughness $(\mu \mathrm{m})$ & Input variable & $1.0-6.8$ \\
\hline Final roughness $(\mu \mathrm{m})$ & Output variable & $0.2-6.2$ \\
\hline
\end{tabular}


Table 3. Results for the different methods.

\begin{tabular}{|l|c|c|c|}
\hline \multicolumn{1}{|c|}{ Method } & MAE & RMSE & CC \\
\hline Bagging Trees & 0.2948 & 0.4241 & 0.9237 \\
\hline Regression Tree & 0.3391 & 0.4870 & 0.9043 \\
\hline Support Vector Machine & 0.3777 & 0.5825 & 0.8650 \\
\hline Nearest Neighbor & 0.4279 & 0.6597 & 0.8429 \\
\hline Multilayer Perceptron & 0.5260 & 0.7279 & 0.8253 \\
\hline RBF Network & 0.5291 & 0.8039 & 0.7399 \\
\hline Linear Regression & 0.5903 & 0.8411 & 0.7245 \\
\hline
\end{tabular}

